\title{
Inlet tube spacing and protrusion inlet effects on multiple circular tubes in the laminar, transitional and turbulent flow regimes
}

\author{
Josua P. Meyer ${ }^{*}$, Marilize Everts, Andrew T.C. Hall, Franscois A. Mulock-Houwer, Martin \\ Joubert, Leslie M.J. Pallent, and Erin S. Vause
}

Department of Mechanical and Aeronautical Engineering, University of Pretoria, Pretoria, Private Bag X20, Hatfield, 0028, South Africa

*Corresponding author: Tel: +27 12420 3014, E-mail: josua.meyer@up.ac.za

\section{Highlights}

- Inlet effects of tube spacing and a protrusion inlet on transitional flow.

- Inlet flow maldistribution delayed and decreased the transitional flow regime.

- Decreased tube spacing led to increased maldistribution.

- Free convection dampened maldistribution effect for a square-edged inlet.

- Free convection did not dampen maldistribution effect due to protrusion inlet.

\begin{abstract}
The purpose of this study was to investigate inlet tube spacing and protrusion effects on multiple circular tubes in the laminar, transitional and turbulent flow regimes. An experimental set-up was built for this investigation and three configurations of test sections were investigated. The first was a single-tube test section for validation purposes, of which the results were compared with literature. The second was two multi-tube test sections with three tubes spaced at different pitches. The third configuration was similar to configuration two, except that the centre tube had a small protrusion. All the tubes had an inner diameter of $3.97 \mathrm{~mm}$, and long tube lengths of $6 \mathrm{~m}$ were used to ensure fully developed flow. The tubes were electrically heated that ensured a constant heat flux heating condition. Water was used as the test fluid, and the Prandtl number varied between 3 and 7 . The experiments were conducted at heat fluxes of 2,3 and $4 \mathrm{~kW} / \mathrm{m}^{2}$ for Reynolds numbers between 1000 and 7 000, to ensure that the transitional flow regime, as well as sufficient parts of the laminar and turbulent flow regimes, were covered. The tubes were spaced apart from each other at 1.25, 1.4 and 1.5 times the outer tube diameter, and the protrusion of the centre tube was $10 \%$ of the tube inner diameter. It was found that an increased pitch ratio dampened the
\end{abstract}


inlet disturbances in the centre tube and reduced the flow asymmetry in the side tubes, therefore the differences in the critical Reynolds numbers and transition gradients of the three tubes decreased. As the inlet disturbances were damped in the centre tube, transitional was delayed compared to a single tube with a square-edged inlet. For the side tubes, the increased flow asymmetry led to increased Reynolds numbers, as well as increased transition gradients. The presence of a protrusion inlet in the centre tube significantly increased the asymmetry of the flow in the side tubes, which led to an additional increase in the critical Reynolds numbers and the transition gradients increased. Free convection effects also led to increased critical Reynolds numbers and transition gradients, as well as decreased differences between the results of the tubes in the multi-tube set-up when a square-edged inlet was used. However, free convection effects were not able to dampen the inlet disturbances caused by a protrusion inlet in the centre tube.

Keywords: Transition, inlet effects, maldistribution, protrusion, tube spacing, friction factor, heat transfer coefficient, multiple tubes, heat exchangers, shell and tube, pitch

\section{NOMENCLATURE}

$\begin{array}{llll}A & \text { Area } & M & \text { Measurement or calculated value } \\ a & \text { Annular diameter ratio } & \dot{m} & \text { Mass flow rate } \\ C & \text { Constant used in correlations } & N u & \text { Nusselt number } \\ C_{p} & \text { Constant pressure specific heat } & P & \text { Pressure } \\ D & \text { Inner diameter } & P r & \text { Prandtl number } \\ D_{h} & \text { Hydraulic diameter } & \dot{Q}_{e} & \text { Electric heat input rate } \\ D_{o} & \text { Outer diameter } & \dot{Q}_{w} & \text { Water heat transfer rate } \\ E B & \text { Energy balance } & \dot{q} & \text { Heat flux } \\ f & \text { Friction factor } & R_{t u b e} & \text { Tube thermal resistance } \\ f_{c r} & \text { Friction factor at } R e_{c r} & R e & \text { Reynolds number } \\ f_{q t} & \text { Friction factor at } R e_{q t} & R e_{c r} & \text { Critical Reynolds number } \\ G z & \text { Graetz number } & R e_{q t} & \text { Start of quasi-turbulent regime } \\ h & \text { Heat transfer coefficient } & \Delta R e & \text { Width of transitional flow regime } \\ I & \text { Current } & T & \text { Temperature } \\ i & \text { Data point index } & t & \text { Protrusion distance (Fig. 1(f)) } \\ j & \text { Colburn } j \text {-factor } & T G_{f} & \text { Transition gradient in terms of } \\ j_{c r} & \text { Colburn } j \text {-factor at } R e_{c r} & & \text { friction factor results } \\ j_{q t} & \text { Colburn } j \text {-factor at } R e_{q t} & T G_{j} & \text { Transition gradient in terms of } \\ k & \text { Thermal conductivity } & & \text { Colburn } j \text {-factor results } \\ L & \text { Length } & V & \text { Velocity/voltage } \\ L_{F D} & \text { Fully developed tube length } & x & \text { Distance from inlet } \\ & \text { between pressure taps P1 and P2 } & & \\ & \text { in Fig. 3 } & \text { Greek letters } \\ L_{t} & \text { Thermal entrance length } & \delta & \text { Uncertainty } \\ & & & \end{array}$




\begin{tabular}{llll}
$\varepsilon$ & Surface roughness & $c$ & Cross-section \\
$\lambda$ & Annular geometric parameter & cor & Correlation \\
$\mu$ & Dynamic viscosity & exp & Experimental \\
$\rho$ & Density & $i$ & Inlet \\
\multicolumn{2}{l}{ Subscripts } & $m$ & Mean \\
$b \quad$ Bulk & $o$ & Outer/outlet \\
a & $s$ & Heat transfer surface
\end{tabular}

\section{Introduction}

Flow maldistributions from inlets and the headers into parallel channels typically used in heat exchangers are frequently encountered in heat transfer equipment, such as condensers, boilers, evaporators, solar energy flat plate collectors, air-to-air plate heat exchangers, automobile radiators, fuel cells, microchannel heat exchangers, as well as in nuclear cooling systems. According to the Scopus ${ }^{\circledR}$ abstract and citation database of Elsevier, 710 papers have been published with the keyword "protrusion" in the title. Only 42 of these papers are related to thermal and/or fluid sciences. In most of these papers protrusions were investigated as a heat transfer enhancement mechanism, such as in references [1-7], however, it was not investigated as part of inlet effects.

More than 210 articles were published with the keyword "maldistribution" in the title, more than 380 with the keywords "inlet" and "design", more than 150 with the keywords "inlet" and "geometry", and more than 50 with the three keywords "inlet", "design" and "geometry". Furthermore, more than 390 articles were published with the keywords "entrance" and "effects", and more than 70 with the keywords "entrance" and "design". Of all these papers, only two [8,9] were review papers. The paper of Mueller and Chou [8] is a general review, more applicable to industrial type of heat exchangers (including shell-andtube heat exchangers), while the paper of Tang et al. [9] focused on micro-channels.

The review paper of Mueller and Chou [8] discussed the different types of maldistributions and their causes. Recommendations were given to avoid maldistributions, and it was concluded that although the performance loss in many cases might be small, the associated mechanical problems can be severe. According to Mueller and Chou: "The prefix mal means defective or bad, and thus the meaning of the term maldistribution depends on how one defines distribution. If a comparison is made to a uniform distribution, then how is uniform defined? For a tube-side flow through a bundle of tubes, a uniform distribution can mean an equal amount of fluid in each tube (the "normal" definition), or that each particle of fluid has an equal residence time in each tube (this would be "plug" flow)". They also 
pointed out that for flow across a tube bundle, the definition gets more complex since the local velocities are changing as the fluid flows through the bundle, as well as other factors such as by-passing and leakages.

Mueller and Chou [8] categorized maldistributions into four categories which are: (1) mechanical causes, (2) self-induced maldistribution due to the changing viscosities with heat transfer (especially in laminar flow), and thermoacoustic oscillations in some heat exchangers, (3) two-phase (gas-liquid) heat exchangers in which it is challenging to uniformly distribute all the flow through a tube bundle, and (4) fouling and/or corrosion. Mechanical caused maldistributions were further classified by Mueller and Chou into four subcategories: (1) entry designs which includes entry problems caused by duct, nozzle, and header designs, or the presence of other exchangers, (2) bypass and leakage streams, (3) fabrication tolerances, and (4) shallow bundles.

According to Tang et al. [9], most designers assume that the flow distribution in a multichannel heat exchanger is uniform, but that this is an incorrect assumption as maldistribution occurs in all types of heat exchangers. Flow maldistribution reduces the thermal performance and increases the pumping power, and maldistribution challenges specifically occur in compact heat exchangers with many small channels in a parallel flow configuration. According to Tang et al. [9], Jiao et al. [10] indicated that flow maldistribution can be classified into two types, namely gross maldistribution and passage-to-passage maldistribution. Gross maldistribution is the result of the improper design of the heat exchanger inlets, while passage-to-passage maldistribution occurs due to manufacturing tolerances, fouling, and frosting of condensable impurities.

Except for the two review papers that were discussed, four more papers on flow maldistributions [11-14] were identified as relevant to this study. Lalot et al. [11] presented a numerical and experimental study of the effect of flow nonuniformity on the performance of heat exchangers. A case study is given where reverse flow may occur for poor inlet header design. A proposal is given to homogenize the flow distribution by adding a uniformly perforated grid in the inlet header. It was shown that a flow nonuniformity at the inlet decreased the effectiveness of condensers and counterflow heat exchangers by approximately $7 \%$, while the decrease was up to $25 \%$ for crossflow exchangers.

Wang et al. [12] experimentally and numerically investigated single phase flow in a compact parallel tube heat exchanger. The inlet and outlet of each tube were from a rectangular header with a square cross-section. The effects of different inlet flow conditions were investigated, which included different tube diameters, header size, area ratio, flow 
direction ( $\mathrm{Z}$ and U-type), as well as the effect of gravity. The experimental results (and numerical results) indicated that the flow distribution for the U-tube flow configuration was more uniform than for the Z-type flow configuration. Depending on the inlet mass flow rate, the mass flow ratio at several of the first tubes could be less than $50 \%$ of the last tube of the Z-type configuration. This phenomenon became more pronounced with increasing velocity at the intake conduit. Furthermore, it was found that the maldistribution effects could be decreased by decreasing the branching tube size, or increasing the settling distance at the intake conduit.

The work of Wang et al. [12] was extended to a part II paper [13] in which experimental results were presented of five modified inlet headers (i.e. one trapezoidal, one multi-step, two baffle plates, and one baffle tube header). The most important finding was that significant maldistributions occurred depending on the type of header used. Furthermore, a proposed novel baffle shows substantial improvements of flow non-uniformity.

Salehi et al. [14] numerically investigated the effects of header configuration and baffle location in the header, on the effectiveness of plate heat exchangers. Triangular fin arrays between the plates were also investigated. Six different baffle locations in the header were investigated, as well as five different header geometries. It was found that the optimal location of the inlet baffle at high Reynolds numbers had an insignificant effect on effectiveness. However, for the laminar Reynolds number range from 250 - 3000 , the baffle location significantly affected the effectiveness.

References [1-14] had in common that studies were done on inlet effects on an application level with multiple channels through which flow occurred. This is an important difference to more fundamental studies where only one channel at a time were considered, investigating the effect of the inlet geometry and/or inlet velocity distribution.

Al-Alarabi [15] developed correlations for single channels using limited experimental data from literature, concentrating on specifically the turbulent flow regime, and taking into consideration different inlets. Equations were presented for the average heat transfer coefficients as function of tube length, Reynolds number, and Prandtl number. Three types of inlets were used: (1) Fully developed velocity distribution before heat transfer starts, which is found in practice in concentric type heat exchangers. (2) Uniform velocity distribution caused by a tube entrance in the form of a bellmouth. This type of inlet geometry is used in some heat exchangers to prevent eddies causing erosion at the tube inlet. (3) A shape that caused extra turbulence as the fluid enters the heat transfer tube. This shape may be a sharp- 
edge entrance as found in tubular heat exchangers, or a bend entrance found in double pipe heat exchangers.

The group of Ghajar and co-workers at Oklahoma State University were the first to experimentally investigate the effect of different types of inlets on heat transfer and pressure drop through a single smooth tube. Although the studies concentrated on the transitional flow regime, a range of data was considered that also included data from the laminar and turbulent flow regimes. The types of inlets considered were a re-entrant, squared-edged, and bellmouth inlet. More than 30 publications were generated on this topic, of which the most important results were summarised in the text book of Çengel and Ghajar [16] and a review paper by Meyer [17]. The studies did not only include smooth macrotubes, but also minitubes and enhanced tubes. In general, it was concluded that the inlet geometry had a significant influence on heat transfer and pressure drop in the transitional flow regime, however, the influences were not that significant in the laminar and turbulent flow regimes.

Mohammed [18] conducted experiments in the laminar flow regime in a smooth circular horizontal tube heated at a constant heat flux, using air as the test fluid. Six different inlet geometries were considered. Four of the inlets were calming sections of the same tube diameter that had an isothermal upstream length, which ensured different stages of hydrodynamically fully developed flow, before heating was applied on the downstream part. Thus, the tube diameter did not change, and inlet effects caused by the inlet geometry were damped with the velocity distribution developing towards fully developed (hydrodynamically) flow. The other two inlets were a sharp-edged (square-edged) inlet and bellmouth inlet. The focus was to investigate the effect of the six different inlet geometries on mixed convection heat transfer in the laminar flow regime. It was found that the Nusselt numbers for the bellmouth inlet were higher than for other inlet geometries.

The group of Meyer and co-workers at the University of Pretoria also generated a body of on-going experimental work investigating the effect of different types of inlets on transition. Although the focus was on transition, a lot of laminar and turbulent data were also produced. The types of inlet geometries investigated were the same as the group of Ghajar [16] as well as an inlet with fully developed hydrodynamically flow, similar to Mohammed [18].

A part of this work was reviewed by Meyer [17]. The works included smooth tubes [1926] using a constant wall temperature as well as a constant heat flux boundary condition, a comparison of smooth tubes with enhanced tubes [20, 21, 27], and characteristics of transition when the fluids previously tested (water and glycol) are replaced with a nanofluid [28]. Hysteresis effects were also investigated [20,21] in which experiments were conducted 
in small increasing Reynolds number increments, starting in the laminar flow regime, increasing through the transitional flow regime into the turbulent flow regime. These results were then compared with experiments conducted using decreasing Reynolds numbers, and it was found that the hysteresis effects in the transitional flow regime were negligible.

In micro-channels [29] heat transfer and pressure drop experiments were conducted in three different sized rectangular micro-channels for water in the laminar and transitional flow regimes, using three types of inlets (squared-edged, bellmouth, and swirl inlet). It was found that the critical Reynolds number and the transitional behaviour of the heat transfer coefficients and friction factors were significantly influenced by the type of inlet used. Ndenguma et al. [30,31] conducted an experimental investigation to determine the average heat transfer coefficients and friction factors in the transitional flow regime of a horizontal concentric annular passage. The annular inlet geometry was that of a $90^{\circ} \mathrm{T}$-section fitting, like that found in most practical applications. The flow was in the mixed convection flow regime and was simultaneously hydrodynamic and thermally developing. The experiments were operated at different degrees of longitudinal wall temperature uniformity on the inner wall of the annular passage. It was found that the degree of temperature uniformity on the inner surface of the annular passage had an influence on the transitional Reynolds number range, the heat transfer coefficients, as well as the friction factors. When the influence of the annular dimensions was investigated, an annular geometric parameter $\left(\lambda=a L / D_{h}\right)$ that takes into consideration both the annular diameter ratio and the hydraulic diameter, was proposed [31]. It was found that as the annular geometric parameter increased, the width of the transitional flow regime, as well as the magnitude of the Nusselt numbers and friction factors, decreased.

The literature review showed that previous work can be divided into two categories. The first category is literature on an application and/or system level where inlet effects on multiple tubes (much more than three tubes) were investigated [1-15], and the research methodologies followed were not on a very fundamental level. The second category was more on a fundamental level in which inlet effects on a single tube only were investigated [16-30], as shown in Fig. 1(a). The literature shows that no work has been done in which maldistribution effects were investigated by considering: (1) the effect of an adjacent tube and/or (2) a protrusion at the inlet of a tube.

Theoretically, two tubes (schematically shown as tubes A and B in Fig. 1(b)) closely spaced next to each other should be investigated, but it would be of little practical value as it is challenging to install tubes so close to each other, and the TEMA [32] standard 
recommends a minimum spacing of 1.25 times the outer tube diameter, for cleaning purposes. In a large tube bundle, the flow paths into any specific tube such as tube B in Fig. 1(c), will most probably be influenced in a three-dimensional direction by the adjacent tubes $A, C, D$, and E. Furthermore, each of the adjacent tubes will be surrounded by other tubes that will also have an influence on the inlet flow path. However, before an investigation like this can be conducted, a simpler case of three tubes in a two-dimensional plane, as shown schematically in Fig. 1(d), should first be investigated. Although the inlet flow into tube B, (Fig. 1(d)) would most probably be symmetrical in a two-dimensional plane, such an investigation will give a good indication what will happen in the three-dimensional case. From an experimental point of view, such a study is not as expensive as a three-dimensional geometry (Fig. 1(c)). What also has merit is to investigate the effect of a single additional protrusion inlet (Fig. 1(e) and (f)) with all other tubes installed flush to an inlet header. A protrusion inlet effect sometimes accidently happens during manufacturing.

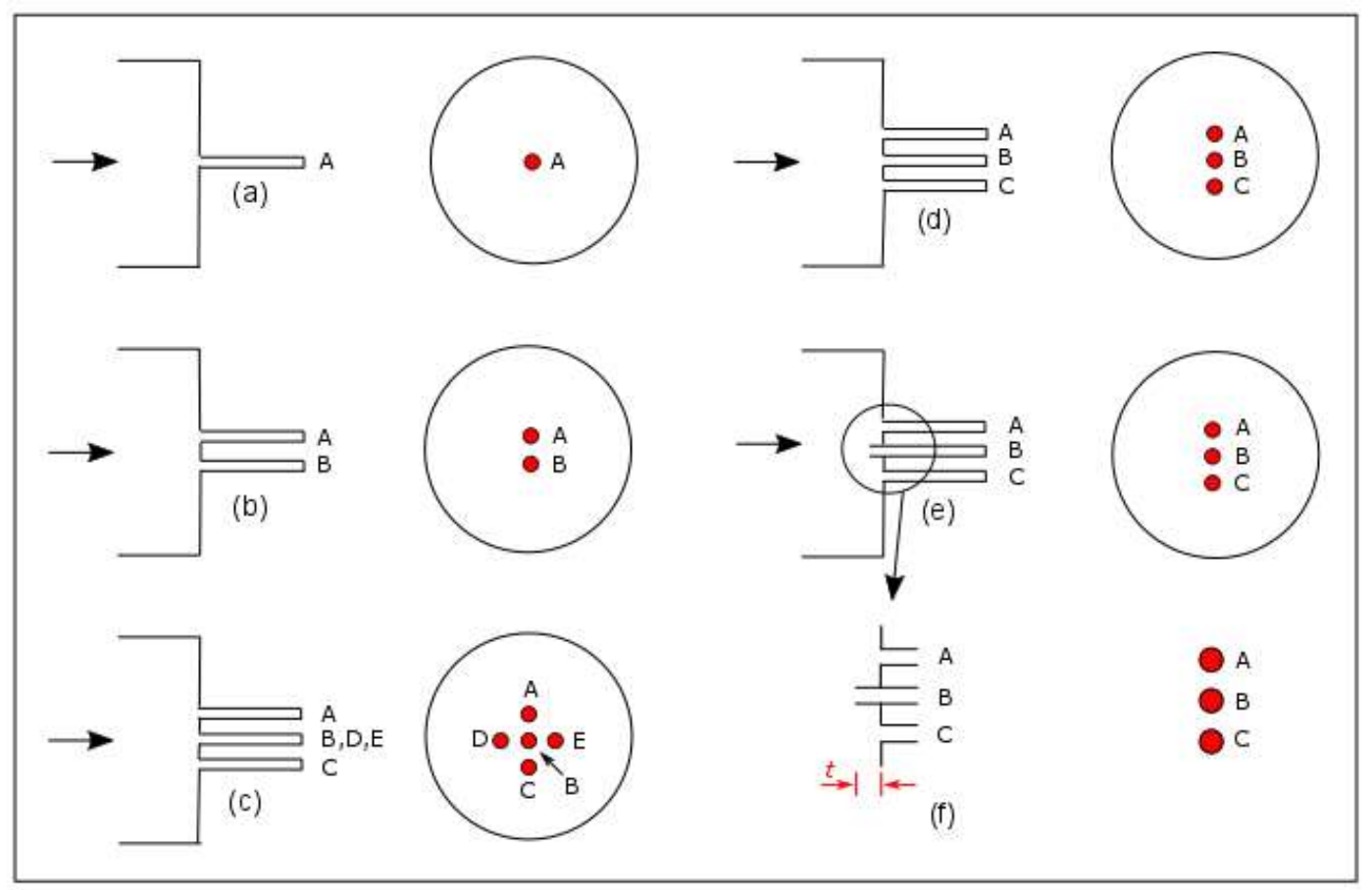

Fig. 1: Different inlet configurations: (a) inlet of a single tube from a calming section, (b) two tubes in parallel, (c) five tubes in parallel in a three-dimensional plane, (d) three tubes in parallel in a two-dimensional plane, (e) three tubes in parallel in a two-dimensional plane with a small protrusion at the centre tube, (f) enlarged view of three tubes, showing a small protrusion at the centre tube. The protrusion distance, $t$, is not to scale in the sketch and was equal to, $t=0.1 D$, with $D$ the tube inner diameter of tubes $A, B$, and $C$.

The purpose of this study was therefore twofold in terms of heat transfer and pressure drop. Firstly, to investigate the maldistribution effects of two adjacent tubes (tubes A and C in Fig. 1(d)) on a centre tube (identified as tube B in Fig. 1(d)). Secondly, to investigate the 
presence of a protrusion inlet (identified as tube B in Fig. 1(e) and (f)) on the two adjacent tubes (tubes $\mathrm{A}$ and $\mathrm{C}$ in Fig. 1(e) and (f)). Note that the protrusion inlet was very small and was caused by the tube not being installed flush into the header as with the other tubes, but installed too deep (with $t=0.1 D$ ) into the header, as schematically shown in Fig. 1(f). Furthermore, it is important to note that Fig. 1(e) is not to scale, and that the protrusion is not comparable to previous studies $[16,19-22]$ where a re-entrant inlet of $1 D$ was investigated. Although the protrusion is geometrically the same as a re-entrant tube, the "re-entrant" distance is an order of magnitude smaller. Heat transfer and pressure drop measurements were taken in the laminar-, transitional-, and turbulent flow regimes and experiments were conducted at different heat fluxes and with the three tubes spaced at different tube pitches. The possible effect of the inlet header geometry on the investigations of this study (Fig. 1(d)(e)), was eliminated by using a square-edged calming section geometry with a large contraction ratio of 58 .

\section{Experimental set-up}

The experimental set-up, shown schematically in Fig. 2, consisted of a closed-loop system that circulated water from a reservoir, through a test section (in which the water was heated and where measurements were taken), back to the reservoir. The $260 \ell$ reservoir was insulated with $50 \mathrm{~mm}$ Armaflex insulation, with a thermal conductivity of $0.034 \mathrm{~W} / \mathrm{m} . \mathrm{K}$. The reservoir was connected to a thermal bath (maximum cooling capacity of $900 \mathrm{~W}$ ) to maintain a reservoir temperature equal to the laboratory ambient temperature, which was kept constant at $21.8^{\circ} \mathrm{C}$. This ensured that the heat transferred to the test fluid was directly from the power supply, and not the surroundings. As the water in the reservoir was potable water, it was continuously circulated through a filter to remove algae, lime scale build-up, unwanted particles, etc. 


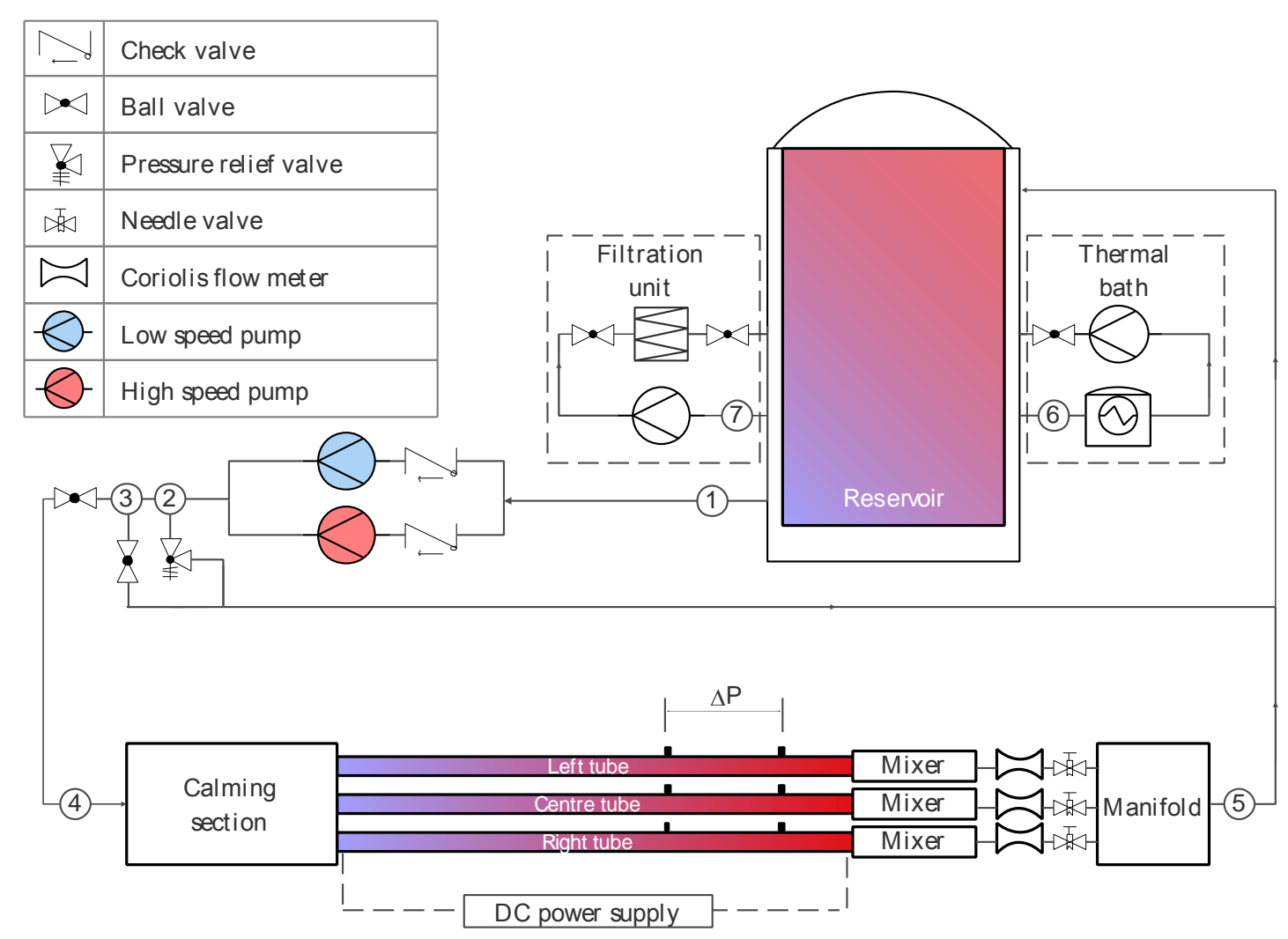

Fig. 2: Schematic representation of the experimental set-up. The test section consisted of three tubes being heated, spaced parallel to each other, and connected to the same calming section. In this study, the three tubes are referred to as the left, centre and right tube, respectively.

The water was circulated by making use of either a low speed pump (variable speed gear pump), or a high-speed pump (variable speed centrifugal pump). Check valves were installed directly upstream of the two pumps, which allowed the user to select the appropriate pump, or to operate both pumps simultaneously.

A bypass line, located downstream of the pumps, allowed flow back to the reservoir without passing through the test section. The result was that the pumps could be operated at much higher speeds to achieve the desired flow rate within the test section. Mass flow rate measurements as a function of time showed that the increased pump speed, together with the increase in backpressure at the pump inlet, decreased the mass flow rate fluctuations in the test section [33].

The test fluid passed through a calming section to the test section, where the temperature, pressure, and flow rate measurements were taken. After the test section (which consisted of either a single tube or three tubes in parallel), the fluid flowed through a manifold with a diameter of $230 \mathrm{~mm}$. Although the manifold collected the flow from the multi-tube set-up and delivered it to the return line of the reservoir, the main purpose was to ensure that the outlet pressures of each tube were the same. Thus, that the geometrical resistances (except 
for the inlet effects caused by three tubes being close to each other, or the protrusion of the centre tube) were all the same.

The calming section was manufactured from a PVC pipe with an inner diameter of $232 \mathrm{~mm}$ and a length of $1.2 \mathrm{~m}$. The design, based on the work of Ghajar and Madon [34], used various stages of fine wire meshing and perforated screens to ensure that a uniform velocity profile was achieved at the inlet of the test section. Pulsations produced by the pump, as well as asymmetric flow caused by partially closed ball valves located upstream of the test section, were damped out in the calming section. Air drawn into circulation accumulated in the calming section due to the large contraction ratio, and was removed through bleed valves. Therefore, the calming section also prevented air from passing through the test section, where it could influence wall temperature and pressure drop measurements. A Pt100 probe, located near the inlet of the calming section, measured the average inlet temperature of the water entering the test section.

The end caps and flanges of the calming section were moulded out of casting epoxy, and turned down to specification on a lathe. A milling machine was used to drill the holes for the different pitch ratios. The stainless steel tubes were slid into the end cap and fixed into position using a mechanical seal. A borescope was used to ensure that the tubes were flush with the face of the endcap for the square-edged inlet, or that the protrusion distance, $t$, was $0.1 D$ (Fig. 1(f)). The protrusion distance was estimated during construction, and after all the experiments were completed, the calming section was disassembled and the protrusion distance was measured with a Vernier calliper.

\subsection{Test section}

The single and multi-tube test sections were manufactured from seamless 316L stainless steel, and was measured with a measuring tape to be $6.0 \mathrm{~m} \mathrm{(} \pm 1 \mathrm{~mm})$ in length. The average inner diameter of the tube was measured as $3.97 \mathrm{~mm}$ with a split-ball unit and Vernier calliper (accuracy of $20 \mu \mathrm{m}$ ), and the outside diameter was measured with a Vernier calliper as $6 \mathrm{~mm}$ (accuracy of $0.076 \mathrm{~mm}$ ). The average surface roughness $(\varepsilon)$ of the tubes was measured using a surface roughness tester, to be approximately $3.45 \times 10^{-5}$, therefore for all practical purposes the tubes can be considered as being smooth.

In this study, the three tubes of the multi-tube set-up will be referred to as "Left tube", "Centre tube", and "Right tube", with the directions given from the point of view of an observer at the calming section, looking in the direction of the flow as shown in Fig. 2. The 
three tubes of the multi-tube set-up were held apart at a uniform distance, equal to that of the pitch ratio, by making use of $3 \mathrm{D}$ printed spacers positioned at $0.5 \mathrm{~m}$ intervals.

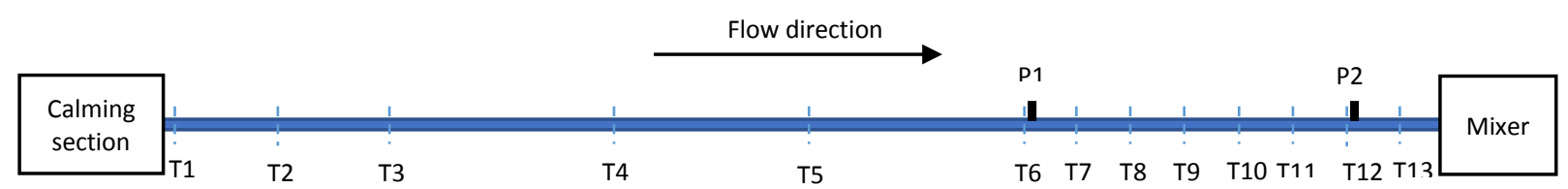

Fig. 3: Schematic representation of the test section. The temperature was measured at thirteen thermocouple stations, $\mathrm{T} 1$ to $\mathrm{T} 13$, and the pressure drop was measured between the two pressure taps P1 and P2. Each thermocouple station contained three thermocouples.

The stainless steel tubes had an electrical resistivity of $74 \mu \Omega \mathrm{cm}\left(\right.$ at $\left.20^{\circ} \mathrm{C}\right)$, and the resistance of the tube was measured to be $0.282 \Omega$ at the lab temperature of $21.8^{\circ} \mathrm{C}$. By passing current directly through the tube, uniform heat fluxes could be maintained with three (one for each tube in the multi-tube set-up) direct current power supplies. The terminals of the power supply were connected to the stainless steel tubes using brass lugs, to ensure that a secure electrical connection could be maintained. The tubes, as well as the connectors, were covered with Kapton film to prevent electrical continuity between adjacent tubes.

To measure the wall temperatures, thirteen thermocouple stations (T1 to T13), consisting of three thermocouples each, were located along the length of each tube (Fig. 3). At each thermocouple station, a thermocouple was placed at the top $\left(0^{\circ}\right)$ and at the bottom $\left(180^{\circ}\right)$. Due to spatial limitations, the third thermocouple was alternated between $90^{\circ}$ and $270^{\circ}$. The thermocouples were glued with Arctic Alumina thermal adhesive (thermal conductivity of $9 \mathrm{~W} / \mathrm{m} . \mathrm{K}$ and a curing time of 5 minutes) into $0.5 \mathrm{~mm}$ deep indentations, drilled $90^{\circ}$ apart on the tube circumference. The stations were measured, marked and drilled using a 3D printed jig, which ensured that all the holes were drilled to the same depth.

The test section was insulated with $155 \mathrm{~mm}$ thick Armaflex insulation. The maximum heat loss (at the maximum heat flux and minimum Reynolds number) was determined to be less than $3 \%$ using the one-dimensional heat conduction equation.

At the time of constructing the test section, the forced convection thermal entrance length was calculated as $L_{t}=C \operatorname{Re} \operatorname{Pr} D$, with $C=0.05$ [16]. The pressure taps were thus silversoldered onto the tubes at axial positions of $4.06 \mathrm{~m}$ and $5.56 \mathrm{~m}$ (1.5 m apart), which was well outside the forced convection theoretical thermal entrance length of $2.8 \mathrm{~m}$ flow (at a Reynolds number of 2000 and Prandtl number of 7). However, according to recent literature [23], $C=0.12$ when the flow is simultaneously hydrodynamically and thermally developing, 
as in this study. This implies that the pressure taps had to be located at $6.7 \mathrm{~m}$ and $8.2 \mathrm{~m}$, which was not only longer than the stainless steel tubes, but also longer than the structure that supported the test sections of the experimental set-up. From the experimental results of Meyer and Everts [23], it follows that the difference between the local laminar Nusselt numbers at $1 / G z=0.05$ and $1 / G z=0.12$, was only $4.4 \%$. Therefore, due the small difference in the magnitude of the local Nusselt numbers between $1 / G z=0.05$ and $1 / G z=0.12$, as well as the limitations of the experimental set-up (tube length and supporting structure length), the flow was considered to be fully developed (this was confirmed experimentally by evaluating the temperature difference between the fluid and inner surface) in the last $1.5 \mathrm{~m}$ of the test section. This was between $1 / G z$ values of 0.07 and 0.1 , which was still significantly greater than 0.05. Furthermore, the average heat transfer coefficients and friction factors in the fully developed section were investigated, which also makes the results "less sensitive" to developing flow, than when the local values are used [25].

The pressure tap holes were drilled to a diameter of $0.4 \mathrm{~mm}$ at a high speed of $30000 \mathrm{rpm}$ to minimize the size of the burrs that formed on the inside of the tube. Furthermore, this was $10 \%$ of the tube inner diameter, to ensure that the hole diameter will not influence the pressure drop measurements [35]. A $4 \mathrm{~mm}$ braided steel cable, wrapped in heat shrink, was then used to remove any burrs resulting from the drilling process, as failure to do so could give errors in the range of $15-20 \%$ [35].

\subsection{Mixer}

The mixers at the outlet of each tube consisted of five alternating splitter plates $(8 \mathrm{~mm}$ wide and $16 \mathrm{~mm}$ long), spaced $90^{\circ}$ apart, as proposed by Bakker et al. [36]. After the water was mixed, it flowed in an axial direction along the Pt100 probe so that the average water outlet temperatures could be measured accurately. This exposed a larger area of the Pt100 probe to the test fluid, eliminated stagnant recirculation zones, and reduced the measurement error and the thermal lag of the system. The mixers were manufactured from acetal and were heavily insulated to minimize the amount of heat loss to the environment. A bleed valve was installed to ensure that the Pt100 probes were completely submerged in the test fluid and that no air was trapped.

\subsection{Instrumentation}

Four Pt100 probes were calibrated in a thermal bath within $0.06^{\circ} \mathrm{C}$ of a DigiCal thermometer with an accuracy of $0.03^{\circ} \mathrm{C}$. The thermocouples were calibrated in-situ to an 
accuracy of $0.1^{\circ} \mathrm{C}$ by pumping water from the thermal bath through the calming section, test section and mixers, and back to the thermal bath. The thermocouples on each tube were calibrated by comparing the measurements to the Pt100 probe at the inlet of the calming section and the three Pt100 probes in the outlet mixers. The calibrations were conducted between temperatures of $20^{\circ}$ and $60^{\circ} \mathrm{C}$.

The pressure taps were connected to Validyne DP15 variable reluctance pressure transducers, and interchangeable diaphragms were used depending on the magnitude of the pressure drop measurements. A diaphragm with a full-scale of $8.6 \mathrm{kPa}$, was used for Reynolds numbers between 1000 and 4 400, while a diaphragm with a full-scale of $22 \mathrm{kPa}$, was used for Reynolds numbers greater than 4400 . The accuracy of the diaphragms was $0.25 \%$ of the full-scale value. The diaphragms were calibrated using a water column, by connecting a Beta T-140 manometer in parallel with the DP15 pressure transducer. The fullscale and accuracy of the manometer was $50 \mathrm{kPa}$ and $50 \mathrm{~Pa}$, respectively.

Elektro-Automatic PS90 40-60 power supplies, that could deliver a maximum current and voltage of $60 \mathrm{~A}$ and $40 \mathrm{~V}$ respectively, were used to maintain constant heat flux boundary conditions of $2 \mathrm{~kW} / \mathrm{m}^{2}, 3 \mathrm{~kW} / \mathrm{m}^{2}$ and $4 \mathrm{~kW} / \mathrm{m}^{2}$, through direct current heating. As the electrical resistivity of the tubes was dependent on temperature and changed during testing, the input currents and voltages were adjusted throughout the experiments to ensure that the desired heat flux was achieved. The power provided to each test section was logged and averaged, to account for small variations during testing.

Three identical Coriolis flow meters downstream of the tubes, were used to measure the mass flow rates in each tube. The accuracy of the calibrated flow meters was $0.05 \%$ of the full-scale value of $110 \mathrm{\ell} / \mathrm{h}$.

\subsection{Experimental procedure}

Using water as the test fluid, experiments were conducted for Reynolds numbers between 1000 and 7000 , ensuring that the transitional flow regime, as well as sufficient parts of the laminar and turbulent flow regimes were covered. Since the effects of hysteresis were found to be negligible in the transitional flow regime [19-21], experiments were conducted for decreasing Reynolds numbers only. This helped to minimize the amount of residual heat stored in the insulation which could negatively influence turbulent results. Reynolds number increments of 200 were used in the turbulent flow regime, 50 in the transitional flow regime, and 100 in the laminar flow regime. 
The set-up was switched on and the pumps were set to operate at maximum speed. The desired mass flow rates were then achieved by adjusting the supply and bypass valves. Any minor corrections were then made by adjusting the voltage supplied to the pump. A high pumping speed was maintained throughout the experiments to reduce flow pulsations. Three different heat fluxes were investigated by setting the supply voltage and current on the power supplies. These values had to be slightly adjusted throughout the experiments to maintain the desired heat flux, as the electrical resistance of the tubes increased with increasing temperatures. Mass flow rates, pressure drops, temperatures, currents and voltages were plotted in real time and monitored, to determine when steady-state conditions were reached. Steady-state conditions were assumed once no measurable changes occurred in the mass flow rates, pressure drops, temperatures, voltages, and currents, for a period of $5 \mathrm{~min}$. Once steady-state conditions were reached, a sample consisting of 200 points were taken at a frequency of $10 \mathrm{~Hz}$. Due to the severe fluctuations in the transitional flow regime, the sample size was increased to 1000 points, to obtain a better representative average. The sample points were averaged to obtain a single data point which was used in the data reduction. Experiments were conducted at lower and higher sampling rates of $1-100 \mathrm{~Hz}$, but no changes in the results were observed.

At lower flow rates, approximately 40 minutes was required to reach steady-state. This $\log$ waiting time was mainly due to the time required for the insulation to reach a constant temperature, since the surface temperatures of the tubes were significantly higher than in the other flow regimes. In the turbulent flow regime, steady-state conditions were reached after approximately 20 minutes, as less heat losses occurred through the insulation material. Approximately 30 minutes was required to reach steady-state in the transitional flow regime, due to the mass flow rate and temperature fluctuations that occurred.

\section{Data reduction}

As a constant heat flux boundary condition was applied to the test section, the average axial temperature of the water increased linearly. The mean fluid temperature, $T_{m}$, at a specific tube location, $x$, was obtained using a linear temperature distribution between the measured inlet, $T_{i}$, and measured outlet, $T_{o}$, temperatures of the fluid over the tube length, $L$.

$$
T_{m}=\left(\frac{T_{o}-T_{i}}{L}\right) x+T_{i}
$$


As this study focussed on fully developed flow, the bulk fluid temperature, $T_{b}$, at $x=4.81 \mathrm{~m}$ in the fully developed section $(4.06 \mathrm{~m}<L<5.56 \mathrm{~m})$ between stations T6 and T12 in Fig. 3, was calculated as:

$$
T_{b}=\left(\frac{T_{o}-T_{i}}{L}\right) 4.81+T_{i}
$$

The properties of water (density, $\rho$, dynamic viscosity, $\mu$, thermal conductivity, $k$, specific heat, $C_{p}$, and Prandtl number, $P r$ ) were determined using the thermophysical correlations for liquid water [37] at the bulk fluid temperature for the average fully developed properties, and at the mean fluid temperature for the local properties at a specific point, $x$, measured from the inlet of the test section.

The Reynolds numbers, $R e$, were calculated as:

$$
R e=\frac{\dot{m} D}{\mu A_{c}}
$$

where $\dot{m}$ was the measured mass flow rate, $D$ was the measured inner diameter, $\mu$ was the dynamic viscosity, and $A_{c}$ the cross-sectional area of the test section $\left(A_{c}=\pi / 4 D^{2}\right)$.

The electrical heat input rate, $\dot{Q}_{e}$, which is the product of the voltage drop, $\Delta V$, and measured current, $I$, remained approximately constant, resulting in a constant heat flux. The heat transfer rate to the water, $\dot{Q}_{w}$, was determined from the measured mass flow rate, measured inlet and outlet temperatures of the water, and the specific heat which was calculated at the bulk fluid temperature:

$$
\dot{Q}_{w}=\dot{m} C_{p}\left(T_{e}-T_{i}\right)
$$

The heat transfer rate to the water, $\dot{Q}_{w}$, was continuously monitored by comparing it to the electrical heat input rate, $\dot{Q}_{e}$, which should ideally be equal since the test section was well insulated. The energy balance, $E B$, which ideally should be as close as possible to zero, was determined as:

$$
E B=\left|\frac{\dot{Q}_{e}-\dot{Q}_{w}}{\dot{Q}_{e}}\right| \times 100=\left|\frac{\Delta V I-\dot{m} C_{p}\left(T_{o}-T_{i}\right)}{\Delta V I}\right| \times 100
$$


The average energy balance of all the experiments that were conducted was less than $3 \%$, which is in good agreement with the calculations estimating the heat losses through the insulation material.

The heat flux, $\dot{q}$, on the inside of the tube wall was determined from the heat transfer rate to the water, $\dot{Q}_{w}$, and the inner surface area, $A_{s}$, of the test section along the heated length:

$$
\dot{q}=\frac{\dot{Q}_{w}}{A_{s}}=\frac{\dot{m} C_{p}\left(T_{o}-T_{i}\right)}{\pi D L}
$$

The heat transfer rate to the water was used to determine the heat flux, since it was regarded as more accurate than the electrical heat input rate. As the energy balance was not zero, and some losses did occur to the ambient air, the electrical input rate was always slightly higher than the heat transfer rate to the water.

The average of the three temperature measurements at each station was used as the average outer surface temperature, $T_{s, o}(x)$, at a specific thermocouple station:

$$
T_{S, o}(x)=\frac{T_{1}+T_{2}+T_{3}}{3}
$$

The thermal resistance, $R_{\text {tube }}$, across the tube wall was calculated using the following equation:

$$
R_{\text {tube }}=\frac{\ln \left(\frac{D_{o}}{D}\right)}{2 \pi k L}
$$

where $D_{o}$ and $D$ were the measured outside and inside diameters of the tube. The thermal conductivity of $316 \mathrm{~L}$ stainless steel is $16.3 \mathrm{~W} / \mathrm{m} . \mathrm{K}$ [38], and the thermal resistance was calculated to be $3.63 \times 10^{-4} \circ \mathrm{C} / \mathrm{W}$. The temperature differences, $\Delta T$, across the tube wall were calculated using the calculated thermal resistance:

$$
\Delta T=\dot{Q}_{w} R_{\text {tube }}
$$

Although the thermocouples were placed in an $0.5 \mathrm{~mm}$ deep indentation in the tube wall, the temperature difference across the remaining $0.5 \mathrm{~mm}$ was approximately $0.11^{\circ} \mathrm{C}$ when the maximum heat input $\left(4 \mathrm{~kW} / \mathrm{m}^{2}\right)$ was applied to the test section. As this was not negligible, the temperature difference calculated using Eqs. (8) and (9) was subtracted from the 
measured surface temperatures (Eq. (7)), to obtain the temperature on the inside of the test section, $T_{s}(x)$, at any axial position on the test section:

$$
T_{S}(x)=T_{s, o}(x)-\Delta T=T_{s, o}(x)-\dot{Q}_{w} R_{t u b e}
$$

As heat was applied to the test sections by passing current through the tube wall (and not using heating wire coiled around the outer surface of the tube), the finite difference formulations of Ghajar and Kim [39] can be used to determine the inner surface temperatures. However, the simpler method of Morcos and Bergles [40], that consists of a two-dimensional conduction equation and also accounts for both radial and peripheral heat transfer, was used. The results were compared with those obtained using Eq. (9), and it was found that at the maximum heat flux of $4 \mathrm{~kW} / \mathrm{m}^{2}$, the difference was $0.05^{\circ} \mathrm{C}$ but reduced to $0.01^{\circ} \mathrm{C}$ when the heat flux was decreased to $1 \mathrm{~kW} / \mathrm{m}^{2}$. As this error approximately and order of magnitude smaller than the uncertainty of the thermocouples $\left(0.1^{\circ} \mathrm{C}\right)$, it confirmed that Eq. (9) was able to provide reliable results. Therefore, similar to Morcos and Bergles [40], it was decided to use the simpler one-dimensional method (Eq. (9)) in this study.

The average inner surface temperatures, $T_{s}$, of the fully developed section, was calculated from the seven measuring stations (T6 to T12), located between $x=4.06$ and $x=5.56(1.5 \mathrm{~m}$ apart), as:

$$
T_{S}=\frac{1}{1.5} \int_{x=4.06}^{x=5.56} T_{S}(x) d x
$$

The average fully developed heat transfer coefficients, $h$, were then determined from the following equation, since the heat flux, $\dot{q}$, inner surface temperature, $T_{s}$, and mean fluid temperature, $T_{m}$, were known:

$$
h=\frac{\dot{q}}{\left(T_{s}-T_{b}\right)}
$$

When axial heat conduction in the tube wall is significant, it needs to be taken into consideration when calculating the heat transfer coefficients [41, 42]. However, using the criteria of Maranzana et al. [43], axial heat conduction was assumed to be negligible, since the axial heat conduction number was orders of magnitude less than 0.01 . 
The average fully developed Nusselt numbers, $\mathrm{Nu}$, were determined from the heat transfer coefficients as follows:

$$
N u=\frac{h D}{k}
$$

The heat transfer results were also investigated in terms of the Colburn $j$-factors, to account for the variations in the Prandtl numbers:

$$
j=\frac{N u}{\operatorname{RePr}^{\frac{1}{3}}}
$$

Eqs. (12) - (14) were for the average fully developed values. The local values at a specific axial position, $x$, was obtained by using the mean fluid temperature (Eq. (1)) and local surface temperature (Eq. (10)), instead of the bulk fluid temperature (Eq. (2)) and average surface temperature (Eq. (11)).

The average friction factors, $f$, were also calculated from the mass flow rate and pressure drop measurements, $\Delta P$, across the fully developed section, $L_{F D}$ :

$$
f=\frac{2 \Delta P D}{L_{F D} \rho V^{2}}=\frac{\Delta P \rho D^{5} \pi^{2}}{8 \dot{m}^{2} L_{F D}}
$$

The definitions and nomenclature of Everts and Meyer [24] were used to obtained the transitional flow characteristics. The critical Reynolds number at which transition started, $R e_{c r}$, was determined as:

$$
R e=R e_{c r} \text { when: }\left(\frac{d j}{d R e}\right)_{i-2: i}=0
$$

The notation $i-2: i$ indicates that at an arbitrary point $i$, the gradient was obtained using the three data points at $\operatorname{Re}(i-2), \operatorname{Re}(i-1)$ and $\operatorname{Re}(i)$, for increasing Reynolds numbers. The end of transition, and the start of the quasi-turbulent flow regime $\left(R e_{q t}\right)$, was determined as [24]:

$$
R e=R e_{q t} \text { when: }\left(\frac{d^{2} N u}{d R e^{2}}\right)_{i: i+2} \geq-0.00015
$$

The notation $i: i+2$ indicates that at an arbitrary point $i$, the gradient was obtained using the three data points at $\operatorname{Re}(i), \operatorname{Re}(i+1)$ and $\operatorname{Re}(i+2)$ for increasing Reynolds numbers (while Eq. (16) used the results at the previous two Reynolds numbers). The width of the transitional 
flow regime, $\Delta R e$, was obtained from the Reynolds numbers at which transition started and ended [24]:

$$
\Delta R e=R e_{q t}-R e_{c r}
$$

The transition gradient, which represents the straight line between the Colburn $j$-factors at the start $\left(R e_{c r}\right)$ and end $\left(R e_{q t}\right)$ of the transitional flow regime, was calculated as follows [24]:

$$
T G_{j}=\frac{j_{q t}-j_{c r}}{R e_{q t}-R e_{c r}}
$$

Similarly, the transition gradient was defined as follows for the friction factor results [25]:

$$
T G_{f}=\frac{f_{q t}-f_{c r}}{R e_{q t}-R e_{c r}}
$$

In general in this study, the percentage error of a measurement or calculated value, $M_{\text {exp }}$, compared to existing correlations, $M_{\text {cor }}$, was determined as \%error $=\left|M_{\text {exp }}-M_{c o r}\right| M_{c o r} * 100$. The average percentage error was taken as the average of the absolute errors of the data points.

\section{Uncertainty analysis}

The method suggested by Dunn [40] was used to calculate the uncertainties, $\delta$, of the parameters obtained in the data reduction, within a 95\% confidence interval. The Reynolds number uncertainties of the single tube are summarised in Fig. 4 for different heat fluxes, as a function of Reynolds number. From this figure it follows that the Reynolds number uncertainties decreased with increasing Reynolds number from approximately $1.7 \%$ to $1.5 \%$ in the laminar flow regime. The mass flow rate fluctuations in the transitional flow regime caused the uncertainties to increase to $2 \%$. The Reynolds number uncertainties remained approximately constant at $1.5 \%$ in the quasi-turbulent and turbulent flow regime. Similar results and trends were also obtained for the multi-tube set-up. The laminar and transitional Reynolds number uncertainties increased slightly with increasing heat flux, due to the increasing free convection effects that led to increased fluctuations inside the test section [24]. It should be noted that the uncertainties in all the flow regimes were very small. The maximum Reynolds number uncertainty of all the tubes and heat fluxes was $2 \%$ and occurred in the transitional flow regime. 


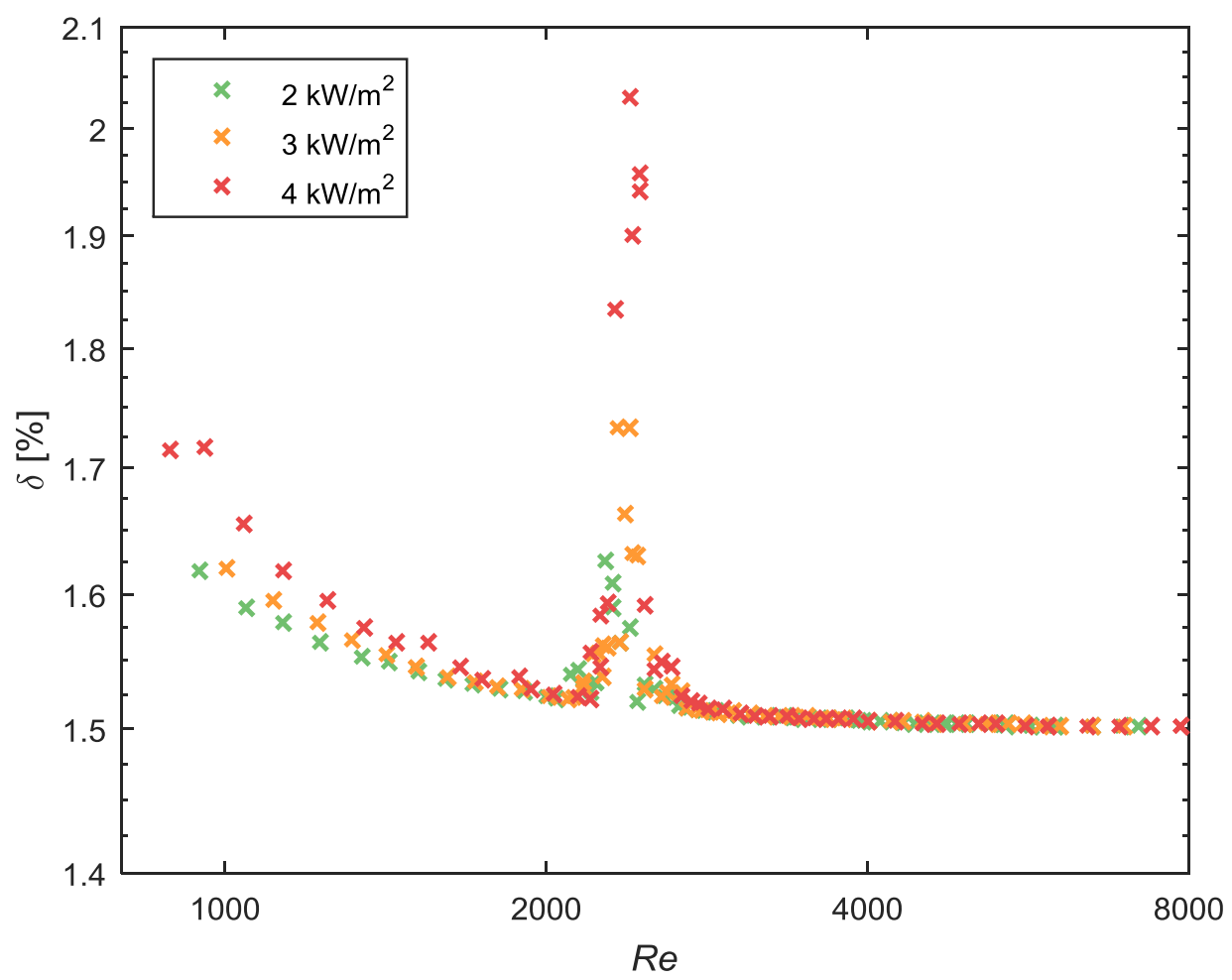

Fig. 4: Reynolds number uncertainty as a function of Reynolds number for heat fluxes of 2,3 and $4 \mathrm{~kW} / \mathrm{m}^{2}$ in the single tube.

The Nusselt number uncertainties of the single tube are summarised in Fig. 5 for different heat fluxes as a function of Reynolds number. From this figure it follows that the Nusselt number uncertainty remained approximately constant in the laminar flow regime, but decreased from $3.4 \%$ to $2.5 \%$ when the heat flux was increased from $2 \mathrm{~kW} / \mathrm{m}^{2}$ to $4 \mathrm{~kW} / \mathrm{m}^{2}$. In the transitional flow regime, the Nusselt number uncertainty increased to approximately $10 \%$ (depending on the heat flux), due to the temperature fluctuations. In general, the standard deviation of the temperature measurements in the laminar and turbulent flow regimes were typically $0.04^{\circ} \mathrm{C}$, however, increased up to $0.28^{\circ} \mathrm{C}$ in the transitional flow regime. The Nusselt number uncertainties in the quasi-turbulent and turbulent flow regime increased with increasing Reynolds number due to the decreased surface-fluid temperature differences. At a Reynolds number of 7000 , the uncertainties decreased from $35 \%$ to $16 \%$ when the heat flux was increased from $2 \mathrm{~kW} / \mathrm{m}^{2}$ to $4 \mathrm{~kW} / \mathrm{m}^{2}$. Although results are shown in this paper for Reynolds numbers greater than 3000 , the focus of this study was on the transitional flow regime which in all cases occurred at Reynolds numbers less than 3000. The Nusselt number uncertainties were therefore less than 13\%. Similar trends were found in the multi-tube set-up. 


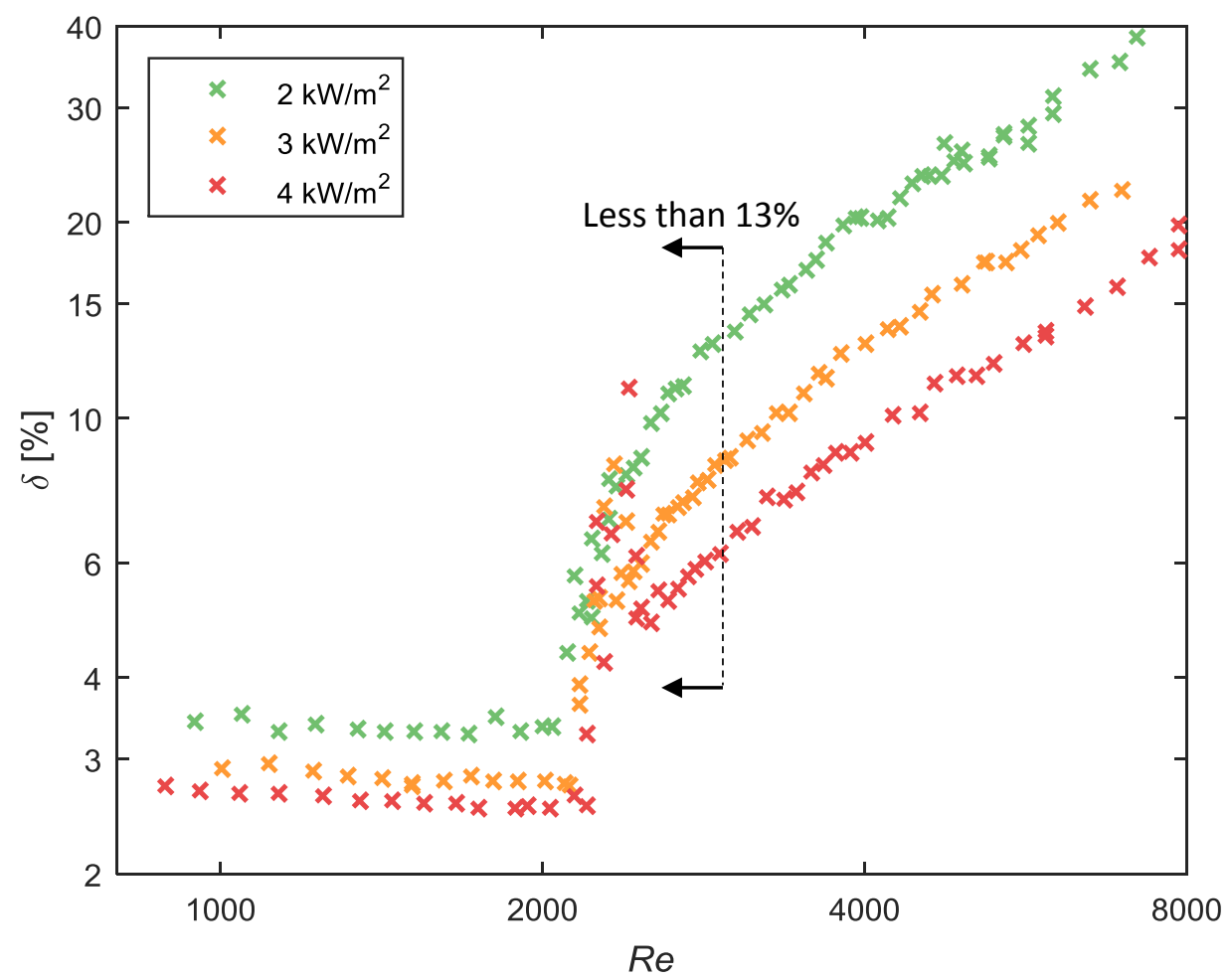

Fig. 5: Nusselt number uncertainty as a function of Reynolds number for heat fluxes of 2,3 and $4 \mathrm{~kW} / \mathrm{m}^{2}$ in the single tube.

The friction factor uncertainties of the single tube are summarised in Fig. 6 for different heat fluxes as a function of Reynolds number. From this graph it follows that at a heat flux of $2 \mathrm{~kW} / \mathrm{m}^{2}$ the friction factor uncertainty in the laminar flow regime decreased with increasing Reynolds number from approximately $14 \%$ at a Reynolds number of 828 , to $9.6 \%$ at a Reynolds number of 2 253. Although the uncertainties increased with increasing heat flux, the uncertainties in the laminar flow regime at a heat flux of $4 \mathrm{~kW} / \mathrm{m}^{2}$ were less than at a heat flux of $3 \mathrm{~kW} / \mathrm{m}^{2}$, which is unexpected. A possible reason might be that the pump was operated at a higher speed at a heat flux of $4 \mathrm{~kW} / \mathrm{m}^{2}$, which resulted in less pulsations, decreased mass flow rate standard deviations and thus decreased uncertainties. In the transitional flow regime, the friction factor uncertainty increased to approximately $10 \%$ (depending on the heat flux), due to the mass flow rate fluctuations that increased with increasing free convection effects [24]. The friction factor uncertainties in the quasiturbulent and turbulent flow regimes remained approximately constant, since it decreased from $9.4 \%$ at a Reynolds number of 2700 to $9.3 \%$ at a Reynolds number of 8000 . Furthermore, there was no significant difference between the uncertainties of the different 
heat fluxes, since free convection effects were suppressed by the velocity of the fluid. Similar trends were found in the multi-tube set-up.

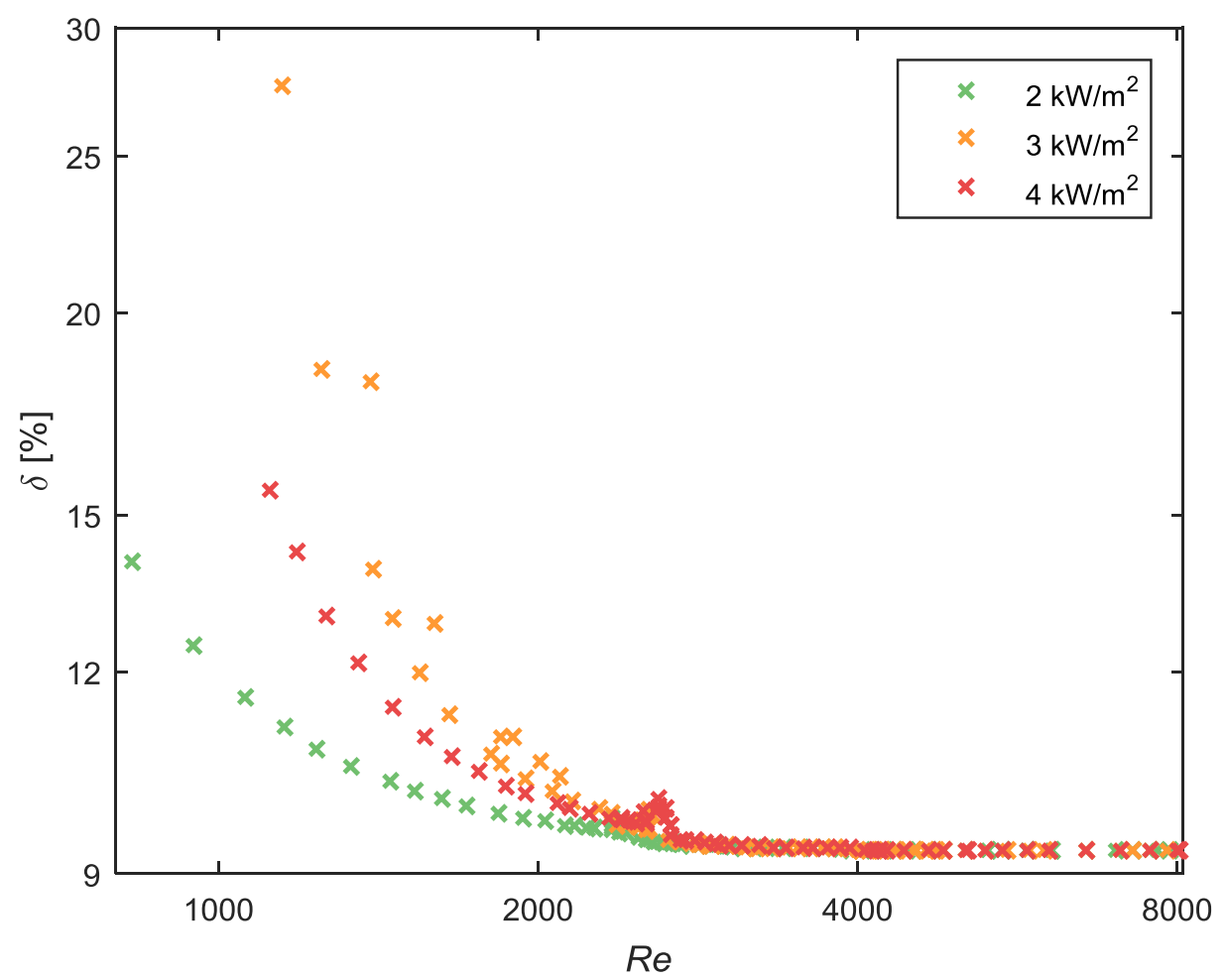

Fig. 6: Friction factor uncertainty as a function of Reynolds number for heat fluxes of 2,3 and $4 \mathrm{~kW} / \mathrm{m}^{2}$ in the single tube.

\section{Validation}

\subsection{Nusselt numbers}

The average fully developed Nusselt numbers at a heat flux of $4 \mathrm{~kW} / \mathrm{m}^{2}$ in the single tube are compared with literature in Fig. 7 for Reynolds numbers between 1000 and 8000 . In the laminar flow regime, the Nusselt numbers correlated well with the correlation of Meyer and Everts [23] for mixed convection laminar flow, with an average deviation of 9\%. The average laminar Nusselt number was 5.54, which is $27 \%$ higher than the theoretical value of 4.36, due to free convection effects inside the tube [23]. As the tube was heated at a constant heat flux, the fluid near the surface had a higher temperature and lower density and circulated in an upward direction (against the direction of gravity), while the fluid near the centre line of the tube had a lower temperature and higher density and therefore circulated downwards. These counter-rotating vortices, also known as free convection effects and secondary flow, were superimposed on the stream-wise main flow and increased the forced convection heat transfer [44]. Metais and Eckert [45] considered free convection effects to be significant when the Nusselt numbers are more than $10 \%$ greater than the corresponding 
forced convection Nusselt numbers which should be 4.36 since the flow is fully developed. Therefore, although the fluid motion in the axial direction of the tube was created by means of a pump, free convection effects remained significant, and mixed convection conditions existed.

At a critical Reynolds number of 2373 , the Nusselt number increased sharply as the flow entered the transitional regime. The Nusselt numbers correlated very well with the correlation of Everts and Meyer [25] in the quasi-turbulent and turbulent flow regimes between Reynolds numbers of 2696 and 8 000, with an average of 3.4\%.

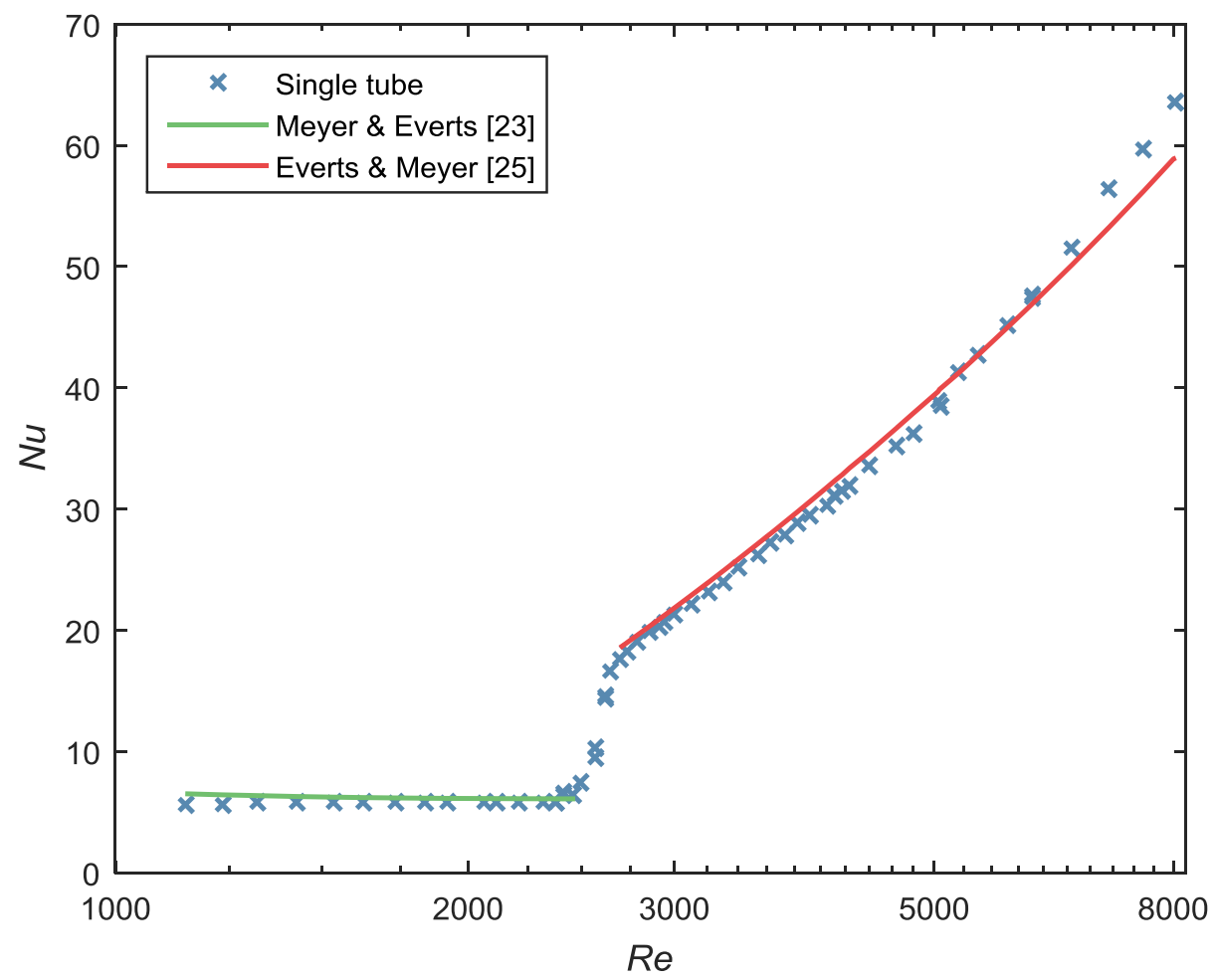

Fig. 7: Comparison with literature $[23,25]$ of average fully developed Nusselt numbers in the single tube at a heat flux of $4 \mathrm{~kW} / \mathrm{m}^{2}$ as a function of Reynolds number.

\subsection{Isothermal friction factors}

Initially, measurements were taken without the addition of heat, to eliminate free convection effects and viscosity variations. Fully developed isothermal friction factors were compared with literature [46] in Fig. 8 for Reynolds numbers between 1000 and 7000 in the single tube. The laminar $(1000<R e<2100)$ friction factors correlated well with the Poiseuille flow friction factor of 64/Re [46] with an average deviation of $1.7 \%$, and a maximum deviation of $1.8 \%$ at a Reynolds number of 1006 . The turbulent (3 $500<R e<7000$ ) friction factors were compared to the Blasius equation [46], and the 
results correlated very well with an average deviation of $1.3 \%$, and a maximum deviation of $2.1 \%$ at a Reynolds number of 3517.

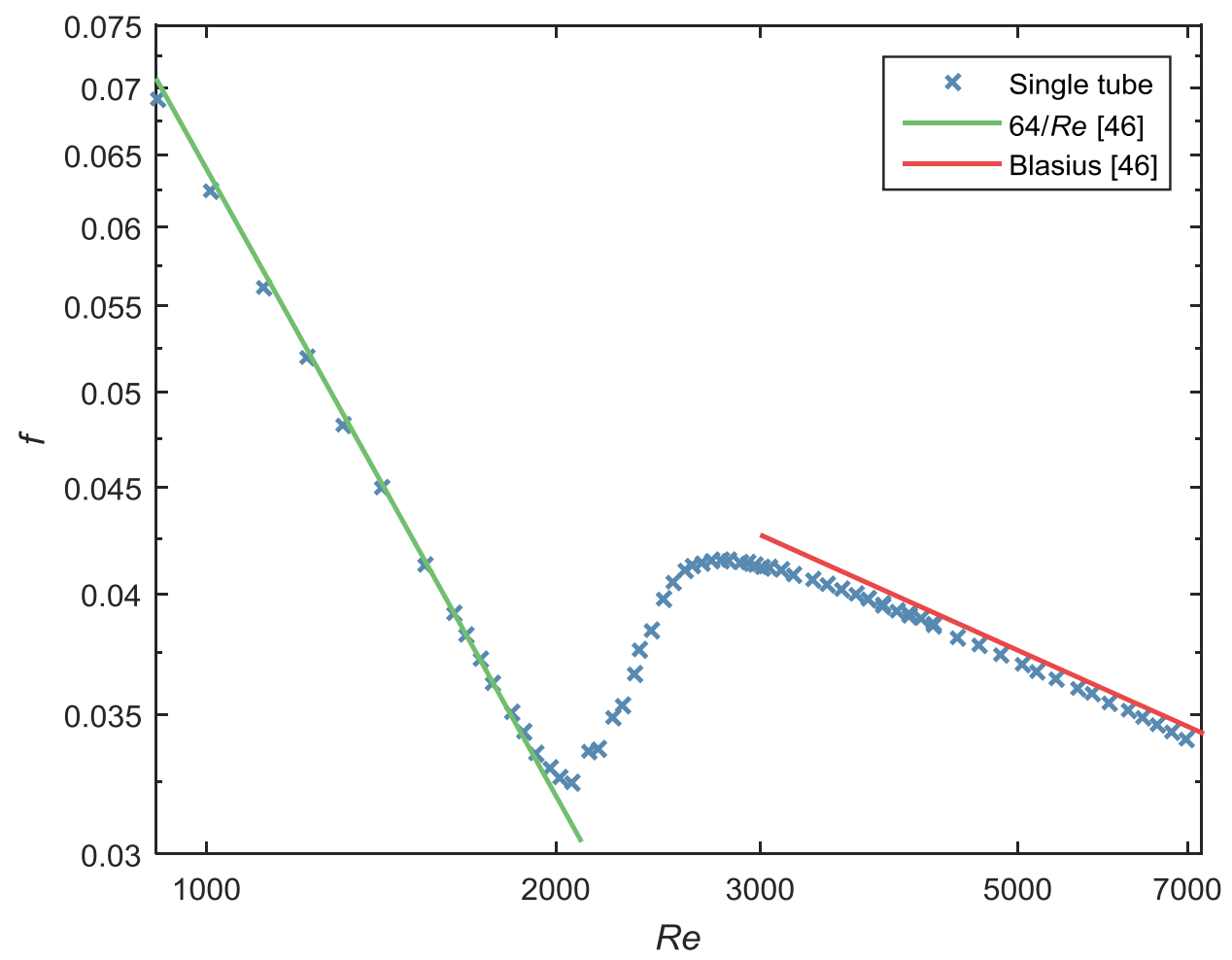

Fig. 8: Comparison with literature [46] of isothermal friction factors in the single tube as a function of Reynolds number.

\subsection{Diabatic friction factors}

Fully developed diabatic friction factors in the single tube for Reynolds numbers between 1000 and 7000 at a heat flux of $4 \mathrm{~kW} / \mathrm{m}^{2}$, were compared with literature in Fig. 9. The laminar friction factors between 1000 and 2300 correlated well with the correlation of Deissler [47], with an average deviation of $2 \%$ and maximum deviation of $2.4 \%$ at a Reynolds number of 1374.

The turbulent friction factors between Reynolds numbers of 3200 and 7000 , were compared to the modified Blasius equation, as presented by Allen and Eckert [48]. The results correlated very well with an average deviation of $1.5 \%$, and a maximum deviation of $3.3 \%$ at a Reynolds number of 3310 . 


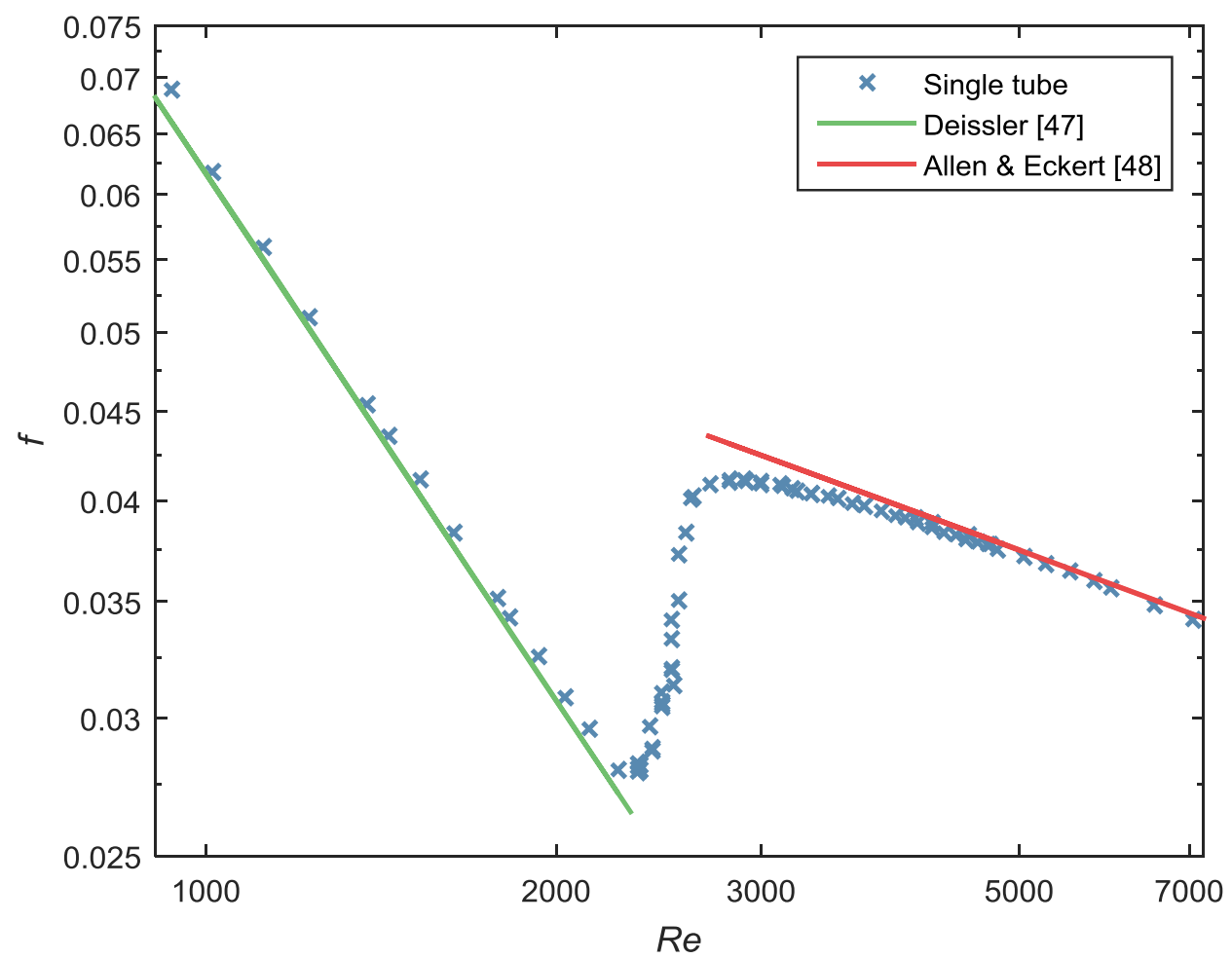

Fig. 9: Comparison with literature $[47,48]$ of diabatic friction factors at a heat flux of $3 \mathrm{~kW} / \mathrm{m}^{2}$ in the single tube as a function of Reynolds number.

\section{Results: Inlet tube spacing}

\subsection{Isothermal friction factors}

The isothermal friction factors obtained in the multi-tube set-up with a pitch of 1.25, are compared to the single tube results in Fig. 10. From this figure it follows that the flow was laminar between Reynolds numbers of 1000 and 2 000, as the friction factors decreased with increasing Reynolds numbers. There was no significant difference in the laminar friction factors of the single tube and multi-tube set-up, since all the data points fell well within the friction factor uncertainty of $9.3 \%$. Closer inspection revealed that the centre, left and right tubes deviated from the single tube by an average of $1.5 \%, 2.2 \%$ and $2.1 \%$, respectively.

Between Reynolds numbers of 3600 and 7000 the isothermal friction factors for the multi-tube set-up also correlated well with the single tube. The average deviation between the friction factors of the single tube and the centre, left and right tubes was $0.3 \%, 2.2 \%$ and $1.3 \%$, respectively. The maximum deviations of $0.4 \%, 2.9 \%$ and $2.5 \%$ for the centre, left and right tubes, respectively, was found at a Reynolds number of approximately 4400 where the pressure transducer diaphragms were changed. It can therefore be concluded that the friction factors in the laminar, quasi-turbulent and turbulent flow regimes were not affected by the adjacent tubes. 


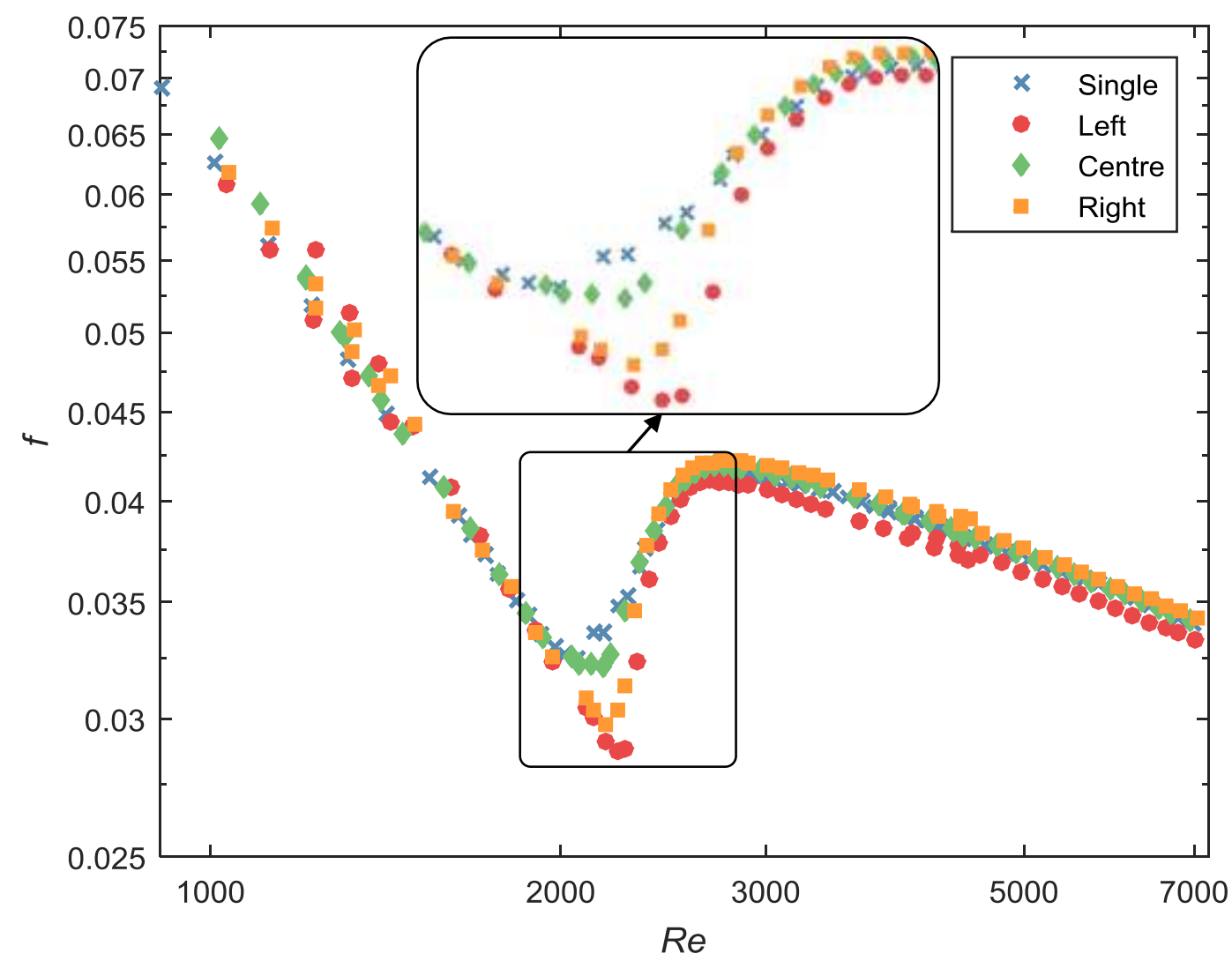

Fig. 10: Comparison of isothermal friction factors as a function of Reynolds number of the single tube and multi-tube setup with a pitch of 1.25 .

The start of transition corresponds to the location where the gradient of the friction factors is zero, before it starts to increase with increasing Reynolds number [25]. Transition started at a Reynolds number of 2067 for the single tube. The centre tube closely followed the behaviour of the single tube, with transition occurring slightly later at a Reynolds number of 2119 . The left and right tubes of the multi-tube setup experienced a significant delay in transition, with critical Reynolds numbers of 2236 and 2 189, respectively. Furthermore, from the detailed view in Fig. 10, it follows that the transition gradients ( $T G_{f}$ as defined in Eq. (20)) of the multi-tube set-up were greater than for the single tube. The transition gradient of the two side tubes were approximately the same and the greatest, while transition gradient of the centre tube was slightly greater than that of the single tube.

From this figure it therefore follows that although the adjacent tubes had a negligible influence on the friction factors in the laminar, quasi-turbulent and turbulent flow regimes, the friction factors in the transitional flow regime were significantly affected. Similar results were obtained in previous studies [19, 34, 49] when the influence of inlet geometries on the fully developed friction factors were investigated. The friction factors in the laminar and 
turbulent flow regimes remained unaffected, while transition occurred first for the inlet with the greatest inlet disturbance. As transition in Fig. 10 occurred first for the single tube, then for the centre tube and last for the two side tubes, it follows that the presence of adjacent tubes decreased the inlet disturbances caused by the square-edged inlet. The effect of the two side tubes on the centre tube was a "smoother" square-edged inlet, therefore the transition was slightly delayed compared to the single tube results. As the tubes were equally spaced, the flow pattern was expected to be symmetric (in the vertical plane) in the centre tube, but asymmetric in the two side tubes. The effect of the centre tube on the side tubes was thus an asymmetric inlet condition that dominated the inlet disturbances (caused by the square-edged inlet), causing a significant delay in transition (similar to a bellmouth inlet).

From literature $[19,34,49]$ it also follows that the transition gradient of a bellmouth inlet was significantly greater than for a square-edged inlet. Meyer and Everts [23] concluded that the laminar-turbulent transition that occurs along the tube length when the Reynolds number exceeds the critical Reynolds number, occurred faster with increasing Reynolds number. This caused the transition region in the tube, as well as the width of the transitional flow regime $(\Delta R e)$ to decrease, and the transition gradient to increase [23, 24]. As transition was delayed for smoother inlet geometries, the critical Reynolds number increased. The increased Reynolds numbers led to a decreased laminar-turbulent transition along the tube length, which in turn led to increased transition gradients. This explains why the transition gradients of the two side tubes, as well as a bellmouth inlet $[19,34,49]$ were greater than for a single tube with a square-edged inlet.

Similar to Fig. 10, the isothermal friction factors of the single tube and multi-tube set-up with a pitch of 1.5, are summarised in Fig. 11. Once again there was no significant difference between the friction factors of the single tube and multi-tube set-up in the laminar, quasiturbulent and turbulent flow regimes. A possible reason for this is that fully developed flow was considered and the friction factors were not affected by the upstream conditions of the flow. Although the transitional flow regime was affected and all three tubes of the multi-tube set-up experienced a delay in transition when compared to the single tube, the difference in the results of the single and multi-tube set-up was less than for the smaller pitch ratio (Fig. 10).

From the detailed view in Fig. 11, it follows that transition started at a Reynolds number of 2129 in the centre tube, while the left and right tubes had critical Reynolds numbers of 2086 and 2176, respectively. Therefore, as the pitch ratio was increased, the critical Reynolds number of the centre tube increased, while it decreased for the two side tubes. 
From Fig. 10 and Fig. 11 it follows that the transition gradient of the centre tube increased with increasing pitch ratio, while it decreased in the two side tubes, however, the transition gradients of the multi-tube set-up remained greater than for the single tube. Therefore, the difference in the transition gradients of the multi-tube set-up, as well as the difference in the critical Reynolds numbers, decreased with increasing pitch ratio.

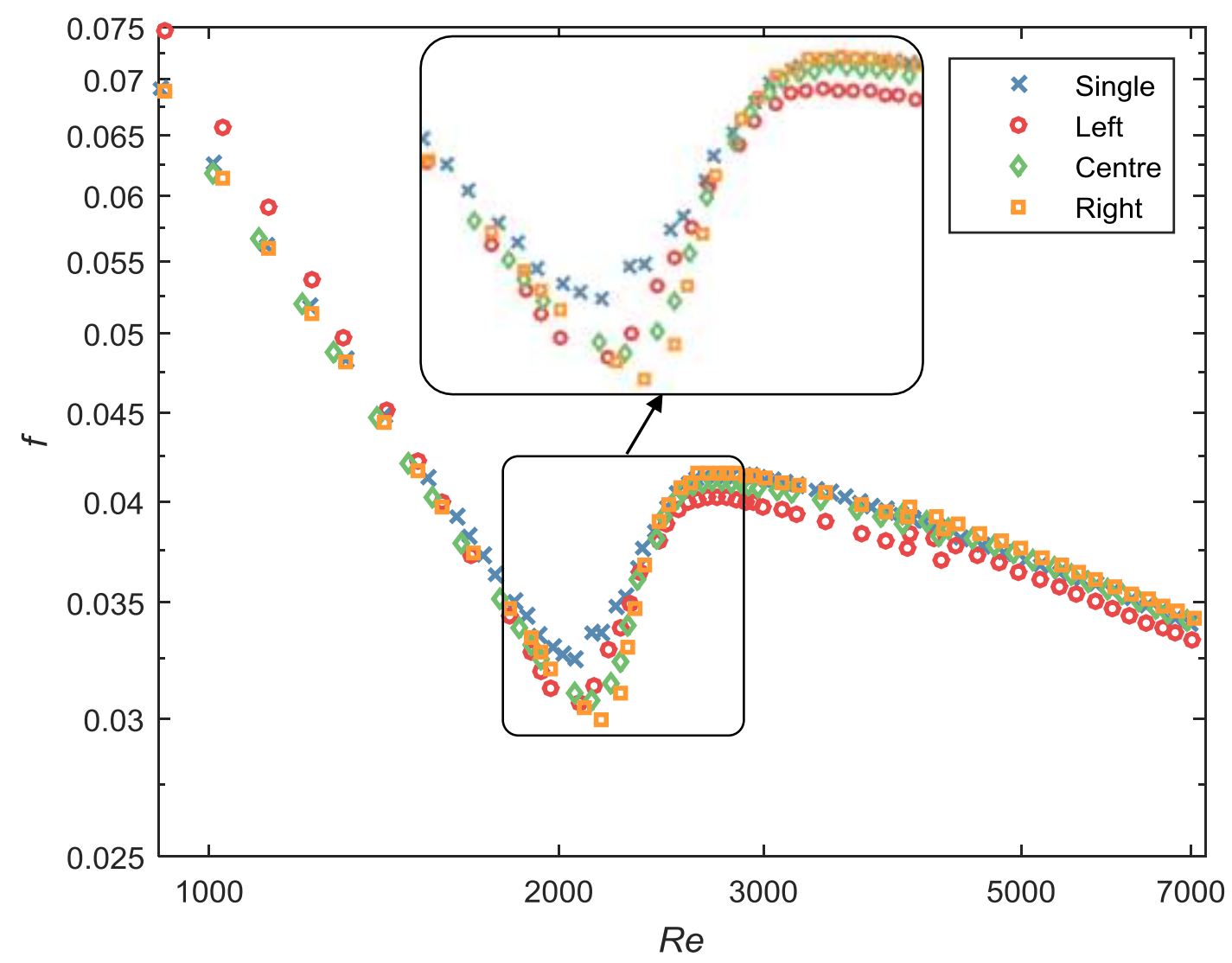

Fig. 11: Comparison of isothermal friction factors as a function of Reynolds number of the single tube and multi-tube setup with a pitch of 1.5 .

To explain this, Fig. 12(b) and (c) contains a simplified schematic representation of what possibly happens with the flow pattern when the pitch ratio is increased, compared to the flow pattern in a single tube (Fig. 12(a)). Fig. 12(d) contains a possible inlet flow pattern for a protrusion inlet (Section 7). It should be noted that the purpose of these graphs is only to illustrate in a two-dimensional plane the effect of the different inlet disturbances on the transition characteristics. Therefore, these flow pattern trends are only postulated and it is recommended that a more accurate representation be obtained using computational fluid dynamic simulations. 
As the pitch ratio was increased, the distance between the tube inlets increased, which caused the recirculation regions between the adjacent tubes (regions $\mathrm{BC}$ and $\mathrm{DE}$ ) to increase, and the average flow gradient at the inlet of the centre tube (arrows B and D) to decrease. Furthermore, the increased recirculation areas had an increased dampening effect on the inlet disturbances caused by the square-edged inlet, therefore, transition in the centre tube was slightly delayed and the transition gradient increased. As the pitch ratio was increased, the asymmetry of the velocity profile (arrows A and E) of the two side tubes decreased and the average flow gradient became closer to that of the centre tube (arrows D and E). Therefore, transition occurred earlier and the difference between the results of the three tubes decreased with increasing pitch ratio. However, as the velocity profile remained asymmetric, transition was still delayed compared to the centre tube and the transition gradients were also greater.

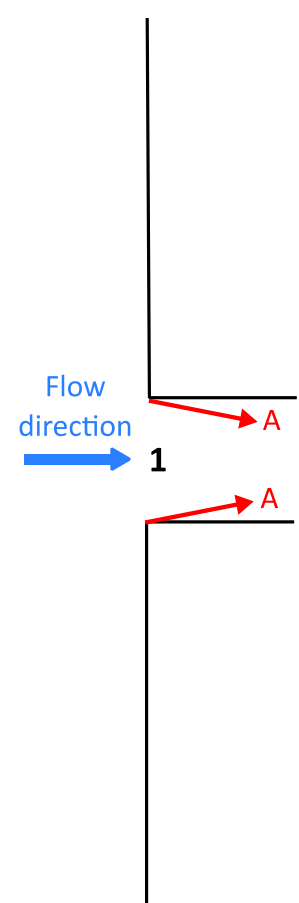

(a)

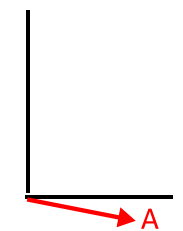

3

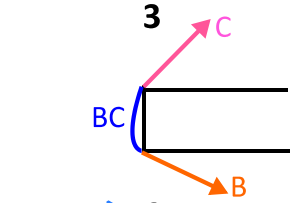

2
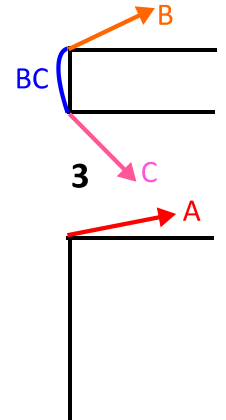

(b)

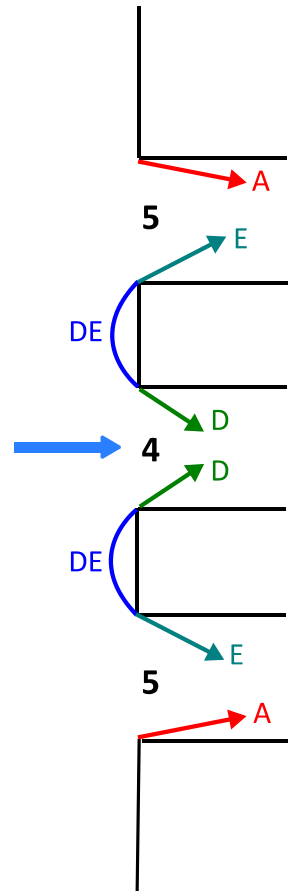

(c)

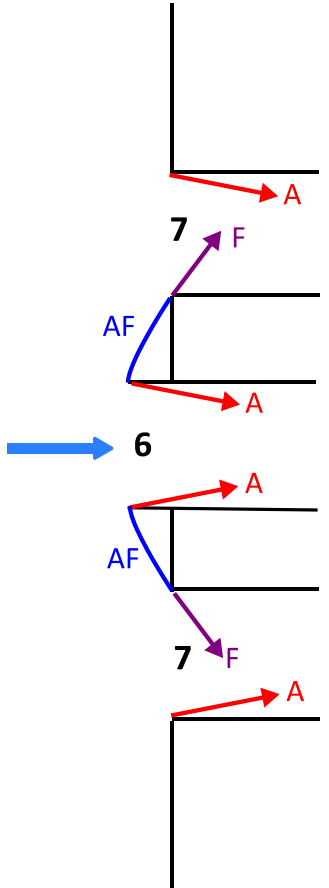

(d)

Fig. 12: Schematic representation of the flow at the inlet of (a) a single tube with a square-edged inlet, (b) three tubes with a square-edged inlet and a pitch ratio of 1.25 , (c) three tubes with a square-edged inlet and a pitch ratio of 1.5 , (d) three tubes with a protrusion inlet at the centre tube and square-edged inlet at the side tubes, and a pitch ratio of 1.4. Arrows $A$ to $F$ represent the average flow gradients at the inlet of the tubes, while regions $B C, D E$ and $A F$, represent the recirculation areas between the adjacent tubes.

From the detailed views in Fig. 10 and Fig. 11 it also follows that the end of transition remained largely unaffected for both pitch ratios, as transition ended in a relatively small band of Reynolds numbers, close to that of the single tube. This is as expected, since the 
flow approached the quasi-turbulent and turbulent flow regimes were the friction factors are independent of inlet geometries, due to the inertia of the fluid.

\subsection{Diabatic friction factors}

Fig. 13 compares the friction factors as a function of Reynolds number for different pitch ratios and heat fluxes in the single and multi-tube set-ups. Similar to the results obtained by Tam et al. [50], the laminar diabatic friction factors decreased slightly compared to the isothermal friction factors, due to the decreasing density and viscosity with increasing temperature. From Fig. 13 it follows that the trend of the laminar diabatic friction factors of both pitch ratios in the multi-tube set-up were similar to the single tube. The friction factors of the left tube were lower than the other tubes across the entire Reynolds number range for all heat fluxes and pitch ratios, pointing to possibly minor geometrical variations in this tube. As all the laminar results were still within the uncertainties, it can be concluded that the slight difference in the inner diameter of the left tube was still within the tolerance guaranteed by the tube manufacturer.

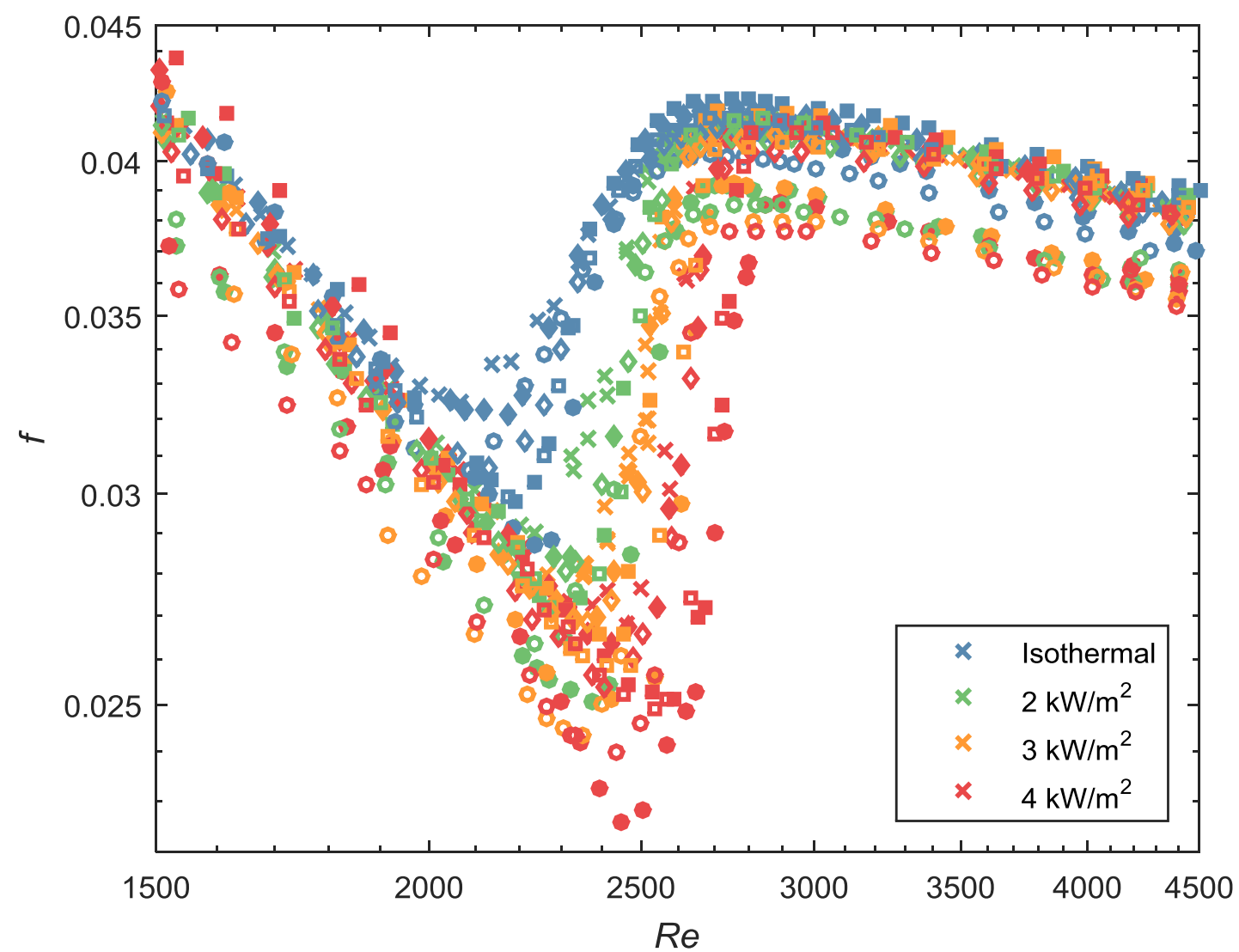

Fig. 13: Comparison of diabatic friction factors as a function of Reynolds number for different pitch ratios and heat fluxes. The isothermal results are coloured blue, while the green, orange and red data represents the results at heat fluxes of $2 \mathrm{~kW} / \mathrm{m}^{2}, 3 \mathrm{~kW} / \mathrm{m}^{2}$, and $4 \mathrm{~kW} / \mathrm{m}^{2}$ respectively. The single tube results are represented by the cross markers $(x)$, while the circles $(0)$, diamonds $(0)$ and squares $(\square)$ represent the results of the left, centre and right tubes of the 
multi-tube set-up. Furthermore, the filled markers represent the results at a pitch of 1.25 , while the empty markers represent the results at a pitch of 1.5 .

The turbulent results for the two pitch ratios were also similar to the single tube and fell within the calculated friction factor uncertainty of approximately 9.2\%. As expected from results in literature $[19,25,49,51]$, there was no significant difference between the results of the different tubes for different pitch ratios and heat fluxes, since the inlet disturbances and free convection effects were suppressed by the inertia of the fluid.

Similar to diabatic friction factor results obtained in previous studies [20, 24, 25, 49], an overall trend in Fig. 13 is that the critical Reynolds number increased for increasing heat fluxes. Similar to the isothermal results, at a heat flux of $2 \mathrm{~kW} / \mathrm{m}^{2}$ and pitch ratio of 1.25 , transition was slightly delayed in the multi-tube set-up compared to the single tube. However, the difference in the critical Reynolds numbers not only decreased when the pitch ratio was increased to 1.5 , but also with increasing heat flux. At a heat flux of $4 \mathrm{~kW} / \mathrm{m}^{2}$, the critical Reynolds numbers of the single, centre, left and right tubes were within $2.5 \%$. It can therefore be concluded that the 'dampening effect' on the centre tube caused by the recirculation areas, as well as the delayed transition caused by the asymmetric flow in the two side tubes, decreased with increasing free convection effects. The end of transition remained largely unaffected for different pitch ratios, as transition ended in a relatively small band of Reynolds numbers, close to that of the single tube. However, similar to the results of Everts and Meyer [24], the Reynolds numbers at which transition ended increased with increasing heat flux, due to the decreasing viscosity with increasing temperature.

From the isothermal results in Fig. 13 it follows that the transition gradients of the multitube set-up was significantly greater than for the single tube. However, as the heat flux was increased, the transition gradients of both the single and multi-tube set-ups increased, and the difference between the transition gradients of the single and multi-tube set-up decreased. Meyer and Everts [23] found that free convection effects caused the flow to transition faster from laminar to turbulent, which caused the transition region inside the test section and the width of the transitional flow regime to decrease, thus the transition gradients increased [24]. As the difference in the critical Reynolds numbers and the transition gradients of the single and multi-tube set-up decreased with increasing heat flux, it can be concluded that free convection effects dominated the effects of adjacent tubes (asymmetric velocity profiles and decreased flow gradients, as schematically illustrated in Fig. 12). 


\subsection{Non-dimensional heat transfer coefficients}

Fig. 14 compares the Colburn $j$-factors as a function of Reynolds number for different pitch ratios and heat fluxes in the single and multi-tube set-ups. Similar to the results obtained by Everts and Meyer [25], it follows from Fig. 14 that free convection had a stronger influence on the Colburn $j$-factors than on the friction factors (Fig. 13) in the laminar flow regime. Although the diabatic friction factors decreased slightly with increasing heat flux, the Colburn $j$-factors in the laminar flow regime increased significantly with increasing heat flux, due to the free convection effects that enhanced the heat transfer inside the test section. The laminar Colburn $j$-factors of the multi-tube set-up was slightly higher (approximately 4\%) than for the single tube, however, there was no significant difference between the Colburn $j$-factors of the three tubes at the different pitch ratios. The Colburn $j$ factors in the quasi-turbulent and turbulent flow regimes were expected to be independent of heat flux, since free convection effects were suppressed by the inertia of the fluid $[24,25]$. However, from Fig. 14 it follows that the Colburn $j$-factors at a heat flux of $2 \mathrm{~kW} / \mathrm{m}^{2}$ were higher than at the other two heat fluxes. This was due to the increased uncertainties (smaller temperature differences) at this heat flux, compared to the other two heat fluxes (Fig. 5).

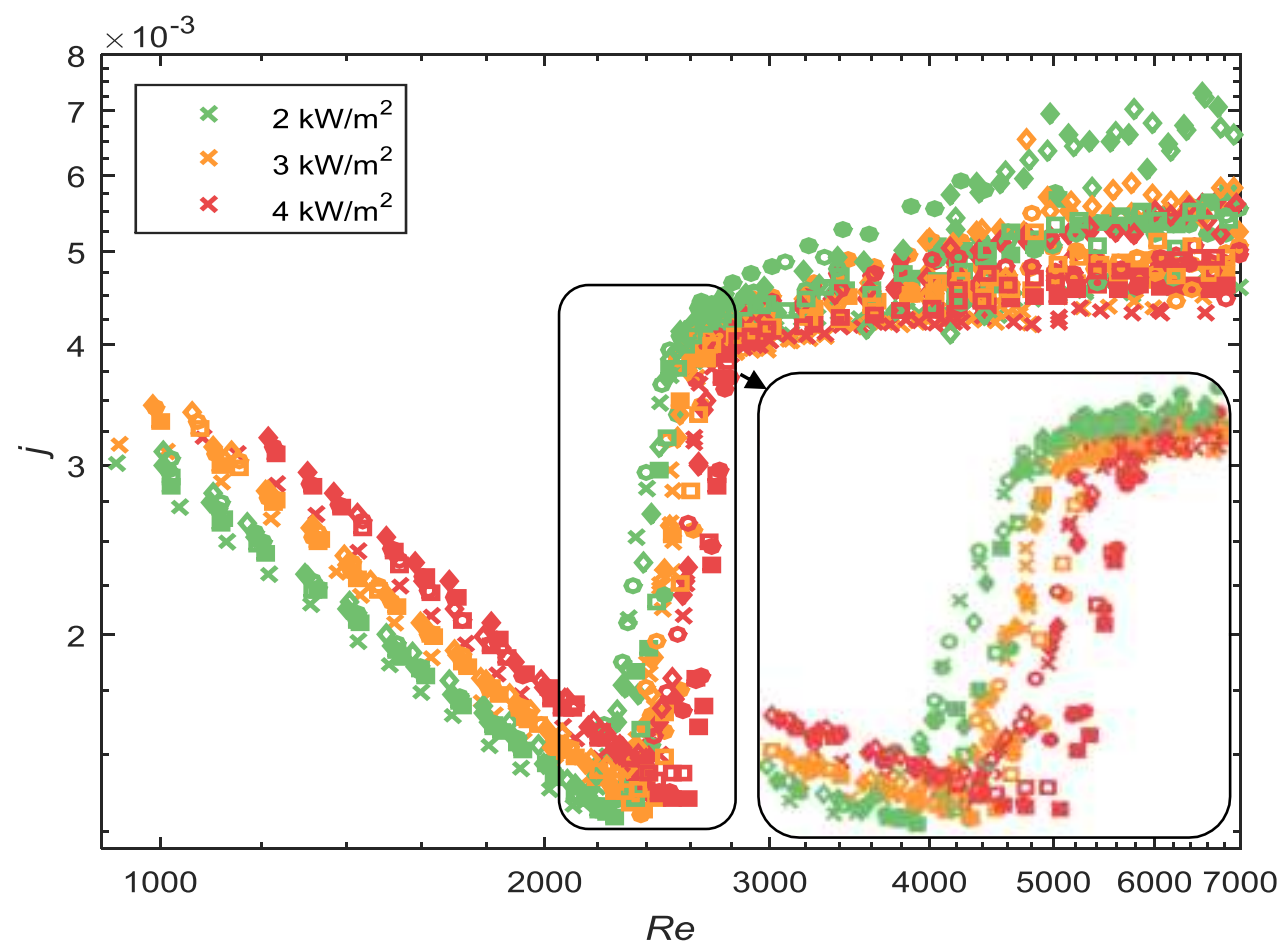

Fig. 14: Comparison of Colburn $j$-factors as a function of Reynolds number for different pitch ratios and heat fluxes. The green, orange and red data represents the results at heat fluxes of $2 \mathrm{~kW} / \mathrm{m}^{2}, 3 \mathrm{~kW} / \mathrm{m}^{2}$, and $4 \mathrm{~kW} / \mathrm{m}^{2}$ respectively. The single tube results are represented by the cross markers $(x)$, while the circles $(0)$, diamonds $(0)$ and squares $(\square)$ represent the results of the left, centre and right tubes of the multi-tube set-up. Furthermore, the filled markers represent the results at a pitch of 1.25, while the empty markers represent the results at a pitch of 1.5. 
To investigate the influence of heat flux and pitch ratio on the transitional flow regime, the Reynolds numbers at which transition started ( $R e_{c r}$ as defined in Eq. (16)) and ended $\left(R e_{q t}\right.$ as defined in Eq. (17)) in Fig. 14, as well as the width of the transitional flow regime ( $\Delta R e$ as defined in Eq. (18)), are compared in Fig. 15. From Fig. 15(a) it follows that both the Reynolds numbers at which transition started and ended increased with increasing heat flux, due to the decreasing viscosity with increasing temperature [24]. The critical Reynolds numbers of the centre tube were similar to that of the single tube, and less than for the two side tubes. Similar to the friction factor results, the difference in the critical Reynolds numbers of the single tube and multi-tube set-up decreased as the pitch ratio was increased to 1.5. Furthermore, as the heat flux was increased, free convection effects dominated the effects of adjacent tubes and the critical Reynolds numbers of the multi-tube set-up approached those of the single tube. Although the Reynolds numbers at which transition ended increased with increasing heat flux, there was no significant trend for the different pitch ratios, since the inlet disturbances were suppressed by the inertia of the fluid.

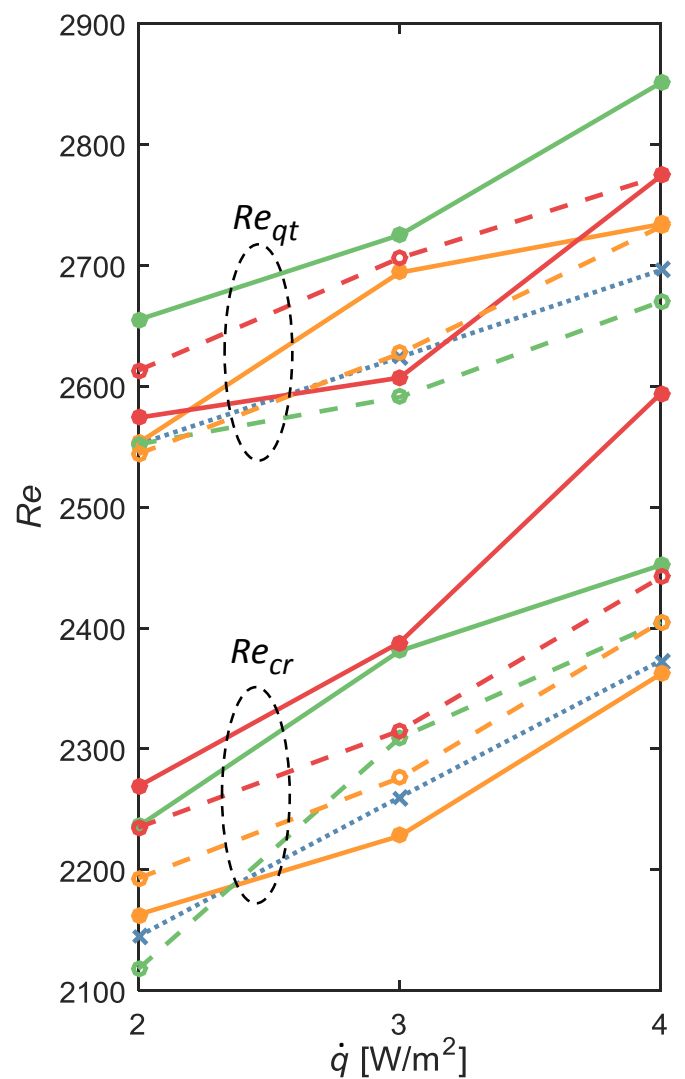

(a)

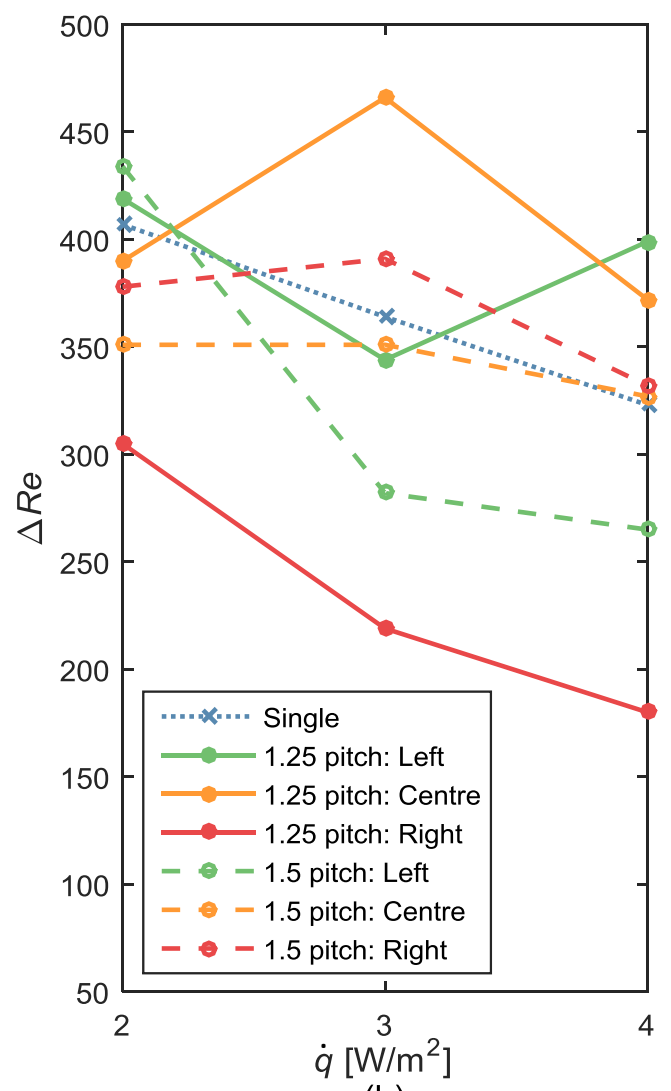

(b)

Fig. 15: Comparison of (a) the Reynolds numbers at which transition started and ended and (b) the width of the transitional flow regime, as a function of heat flux for the single and multi-tube set-ups. The blue data represents the single tube results, while the green, orange and red data represents the left, centre and right tubes, respectively. Furthermore, the solid markers and lines represent the results at a pitch of 1.25 , while the empty markers and dashed lines represents the results at a pitch of 1.5 . 
From Fig. 15(b) it follows that, similar to the results of Everts and Meyer [24], the width of the transitional flow regime decreased with increasing heat flux. As this decrease was significantly less in the centre tube than in the single and side tubes, the effects of the adjacent tubes probably dominated free convection effects.

To investigate the influence of heat flux and pitch ratio on the heat transfer characteristics in the transitional flow regime, the transition gradients $\left(T G_{j}\right.$ as defined in Eq. (19)) of the results in Fig. 14 are compared in Fig. 16. As expected, the transition gradient of the single and side tubes increased with increasing heat flux, since the increased free convection effects caused the flow to transition faster from laminar to turbulent [23, 24]. However, the transition gradient of the centre tube remained unaffected by heat flux, since the inlet disturbances caused by the adjacent tubes dominated free convection effects. Furthermore, the transition gradient of the centre tube was less than for the two side tubes and similar to the single tube, which is in good agreement with the results in Fig. 14 and Fig. 15. As the inlet disturbances were greater in the centre tube, and not dominated by free convection effects, the flow transitioned slower from laminar to turbulent.

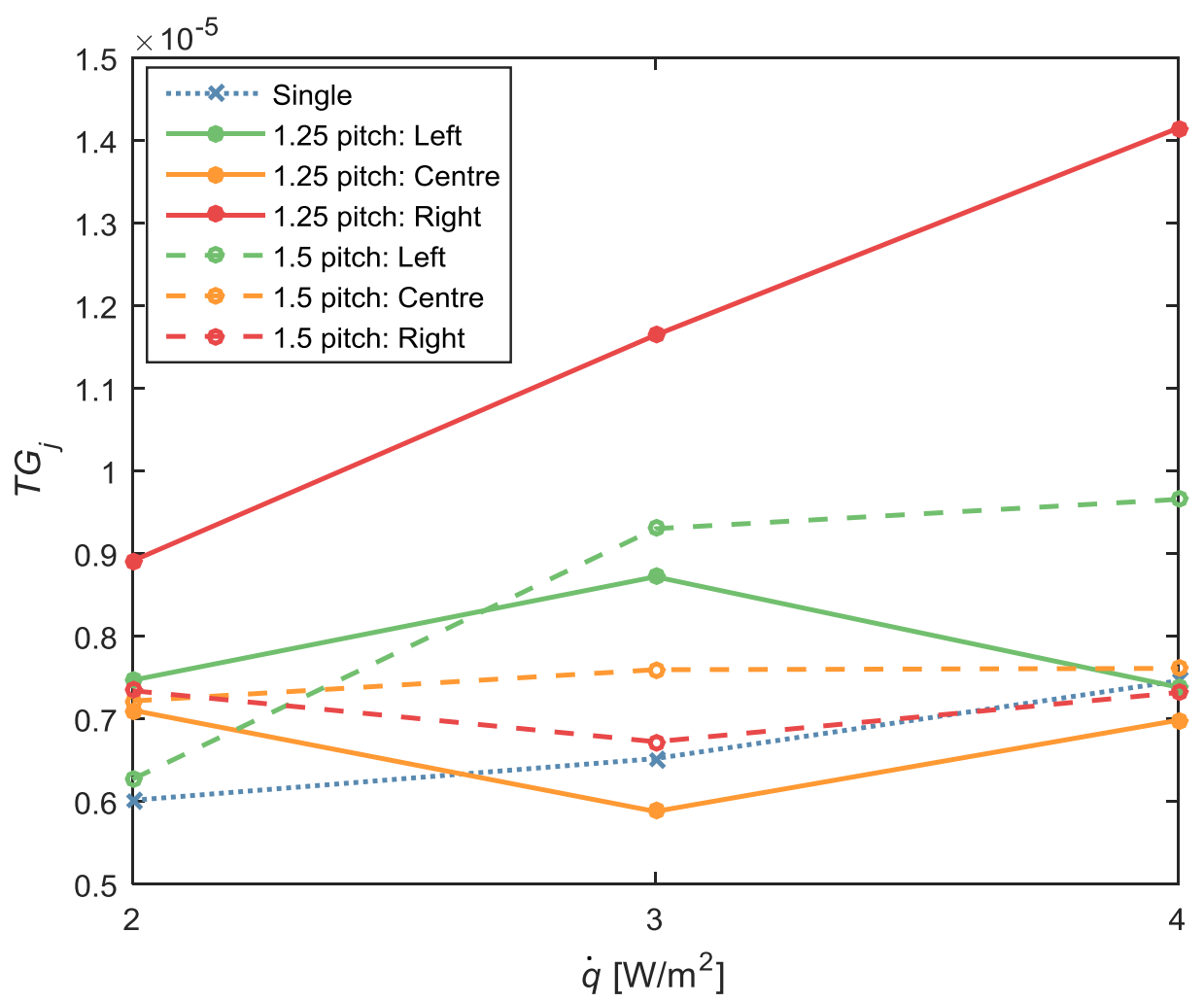

Fig. 16: Comparison of transition gradient, $T G_{j}$, as a function of heat flux for the single and multi-tube set-ups. The blue data represents the single tube results, while the green, orange and red data represents the left, centre and right tubes, respectively. Furthermore, the solid markers and lines represent the results at a pitch of $\mathbf{1 . 2 5}$, while the empty markers and dashed lines represents the results at a pitch of 1.5. 
Similar to the isothermal friction factors in Fig. 10 and Fig. 11, it follows from Fig. 16 that when the pitch ratio was decreased from 1.5 to 1.25 , the transition gradient of the centre tube decreased, while it increased in the two side tubes. Therefore, although free convection effects increased the transition gradients, the increased asymmetry in the side tubes (arrows A and $\mathrm{C}$ compared to arrows $\mathrm{A}$ and $\mathrm{E}$ in Fig. 12) caused by the smaller pitch ratio assisted the flow to transition from laminar to turbulent. However, for the centre tube, the effects of the adjacent tubes decreased with decreasing pitch ratio (decreased recirculation areas, AB, and increased averaged flow gradients, arrow B, in Fig. 12). The inlet disturbances caused by the square-edged inlet was thus less dampened, and the flow transitioned slower from laminar to turbulent.

\section{Results: Protrusion inlet effects}

\subsection{Isothermal friction factors}

To investigate the presence of a protrusion inlet (identified as tube B in Fig. 1(e)-(f)) on the two adjacent tubes (tubes $\mathrm{A}$ and $\mathrm{C}$ in Fig. 1(e)-(f)), the isothermal friction factors of the multi-tube set-up are compared to the single tube results in Fig. 17. Note that the protrusion effect was very small and was caused by the tube not being installed flush into the header as with the other tubes, but installed too deep (with $t=0.1 D$ ) into the header, as shown in Fig. 1(f). Although the protrusion is therefore geometrically the same as a re-entrant tube [34], the "re-entrant distance" is an order of magnitude smaller.

From Fig. 17 it follows that the protrusion inlet had a negligible influence on the friction factors in the laminar, quasi-turbulent and turbulent flow regimes. However, similar to Fig. 10 and Fig. 11, the isothermal friction factors in the transitional flow regime was significantly affected. Transition started at a Reynolds number of 1991 in the single tube and at a Reynolds number of 2125 in the centre tube of the multi-tube set-up, and was significantly delayed to Reynolds numbers of 2706 and 2442 in the left and right tubes, respectively. From literature $[19,34,49]$ it is known that transition occurred first for the re-entrant inlet, since the inlet disturbance was the greatest. However, as the re-entrant distance was very small, and the adjacent tubes dampened the protrusion inlet disturbance (due to recirculation areas AF in Fig. 12). Therefore, transition in the centre tube did not occur earlier compared to the single tube with a square-edged inlet, but was slightly delayed instead. As schematically illustrated in Fig. 12, the protrusion increased the recirculation areas between the tubes, which also increased the asymmetry of the velocity profile of the two side tubes 
(arrows A and F in Fig. 12). This dominated the inlet disturbances caused by the squarededged inlet and caused transition to be significantly delayed in the two side tubes.

Although the transition gradients of the single and centre tubes were similar, the transition gradients of the left and right tubes were significantly greater. As transition was significantly delayed, the increased fluid velocity due to the increased Reynolds numbers, caused the laminar-turbulent transition to occur faster, thus the transition gradient increased. Due to the symmetry with respect to the centre tube, similar results were expected for the left and right tubes. However, from Fig. 17 it follows that transition occurred later in the left tube, thus pointing to again to possibly minor geometrical variations in this tube. The recirculation areas and flow asymmetry caused by the protrusion inlet were significantly greater than for multiple tubes with a square-edged inlet. As the transitional flow regime is sensitive to different inlet conditions, the increased flow asymmetry caused by the protrusion inlet, combined with the geometrical variations inside the left tube, led to increased differences in the transitional flow regime compared to Fig. 13.

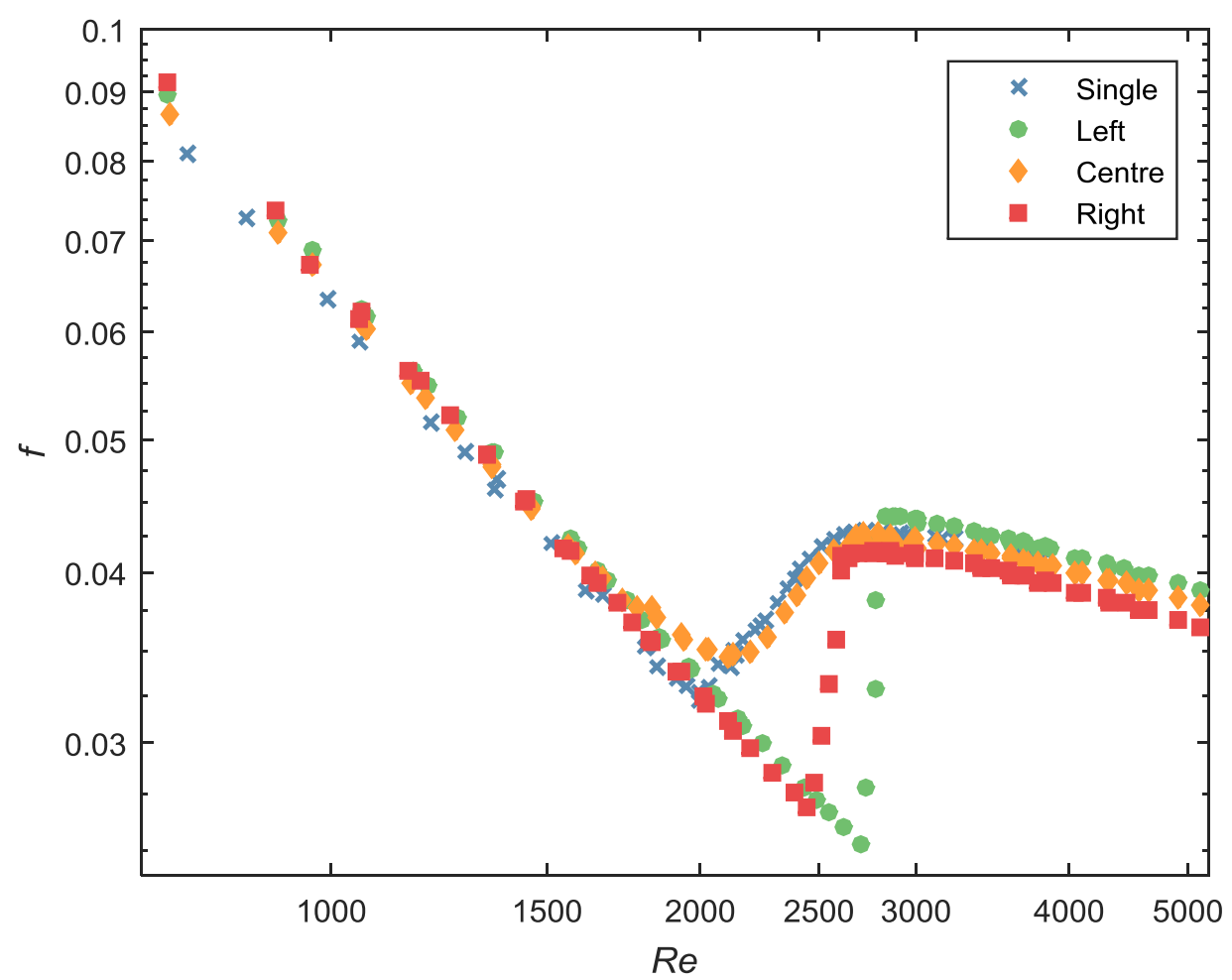

Fig. 17: Comparison of isothermal friction factors as a function of Reynolds number of the multi-tube test section with a protrusion inlet and pitch ratio of 1.4 and the single tube with a square-edged inlet.

From Fig. 17 it also follows that although the protrusion inlet significantly affected the start of the transition, the effect was less on the end of transition. Transition ended at 
Reynolds numbers of 2621 and 2648 in the single and centre tubes, respectively, and at Reynolds numbers of 2839 and 2655 in the left and right tubes, respectively.

To compare the effect of a protrusion inlet to the effect of different pitch ratios on the friction factors in the transitional flow regime, the results of Fig. 10, Fig. 11 and Fig. 17 are compared in Fig. 18 for Reynolds numbers between 1600 and 4000 . From this graph it follows that although transition occurred first in the single tube and then in the centre tube of the protrusion inlet, transition was significantly delayed in the left and right tubes, compared to the square-edged inlet results at different pitch ratios. The difference in the transition gradients of the centre and side tubes was also significantly greater for the multi-tube set-up with a protrusion inlet, due to the increased inlet disturbance that increased the asymmetry of the velocity profile in the two side tubes. The differences in the critical Reynolds numbers and transition gradients of the multi-tube set-up were less for the square-edged inlet at a pitch of 1.25 and became even less when the pitch ratio was increased to 1.5. From Fig. 18 it can therefore be concluded that the protrusion inlet had a significant influence on not only the side tubes, but also on the centre tube, and the difference between the three tubes decreased as the inlet disturbance was decreased.

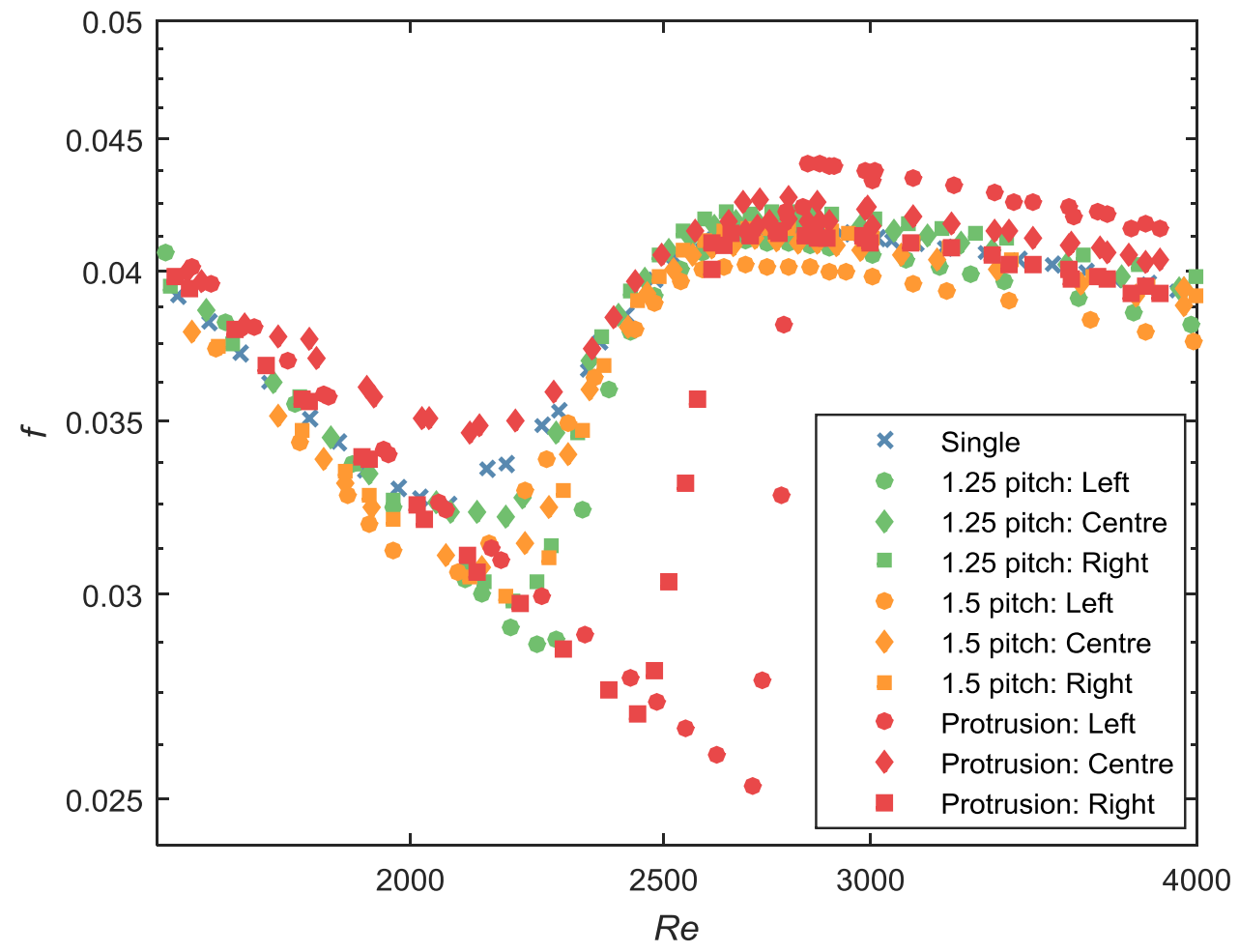

Fig. 18: Comparison of the effect of a protrusion inlet on the isothermal friction factors in the transitional flow regime to the effect of different pitch ratios. 


\subsection{Diabatic friction factors}

To investigate the effect of a protrusion inlet on the diabatic friction factors, the diabatic friction factors at a heat flux of $3 \mathrm{~kW} / \mathrm{m}^{2}$ in the single and multi-tube set-ups are compared in Fig. 19. From this figure it follows that unlike the isothermal case in Fig. 17, transition occurred earlier in the centre tube than in the single tube. However, transition was still significantly delayed in the two side tubes. Everts and Meyer [24] found that free convection effects caused transition to occur earlier (at lower mass flow rates), however, the critical Reynolds numbers increased due to the decreasing viscosity with increasing temperature. When comparing the critical Reynolds numbers in Fig. 17 and Fig. 19, it follows that when a heat flux of was $3 \mathrm{~kW} / \mathrm{m}^{2}$ applied, the increase in critical Reynolds number was approximately 390 for the single tube and 330 for the side tubes, while the critical Reynolds number of the centre tube only increased with a Reynolds number range of 47. However, from the mass flow rates it follows that transition occurred significantly earlier in the centre tube (decrease of approximately 16\%), while the difference in the mass flow rates of the isothermal and diabatic results of the other tubes were almost negligible. Therefore, free convection effects enhanced the "re-entrant effect" of the protrusion inlet, causing transition to occur earlier. The asymmetric velocity profile in the side tubes caused by the protrusion inlet, however, dominated free convection effects, and the increasing critical Reynolds numbers were only due to the variation of fluid properties with temperature [24].

Everts and Meyer [24] also conducted experiments at a heat flux in a $4 \mathrm{~mm}$ single tube with a square-edged inlet at different heat fluxes. As the tube diameter was very small, free convection effects did not significantly (less than $1 \%$ ) decrease the mass flow rate at which transition started when the heat flux was increased from $1 \mathrm{~kW} / \mathrm{m}^{2}$ (forced convection) to $3 \mathrm{~kW} / \mathrm{m}^{2}$, however, the critical Reynolds numbers increased due to the decreasing viscosity with temperature. This explains why, for this study, the mass flow rate at which transition started in the single tube did not significantly differ between the isothermal and diabatic friction factor results.

As expected, the transition gradients increased when heat was applied to the tubes, since free convection effects caused the fluctuations inside the test section to increase, which assisted the flow to transition from laminar to turbulent [24]. The increase in transition gradient of the centre tube was less than for the other tubes, probably due to the greater inlet disturbance caused by the protrusion inlet. 


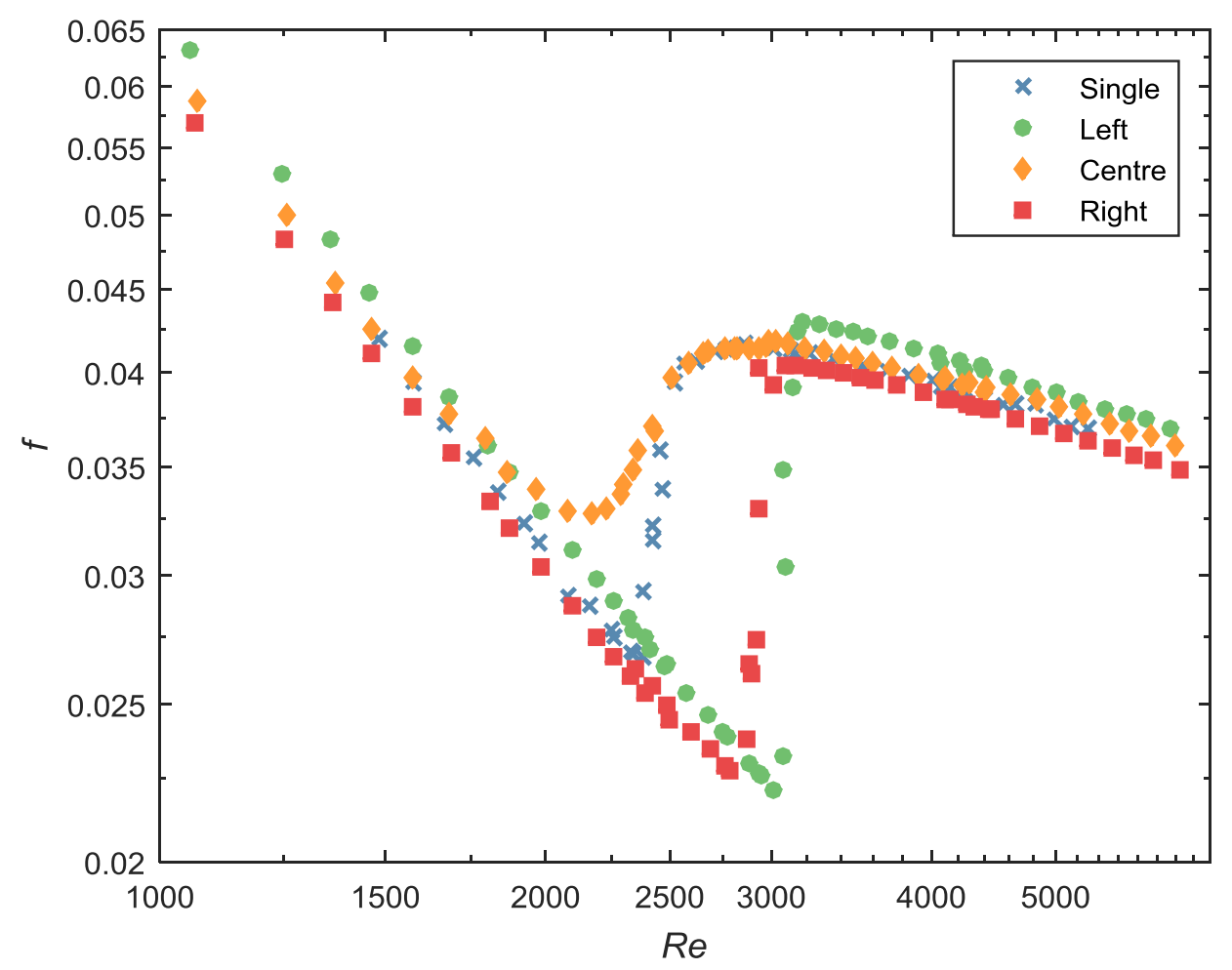

Fig. 19: Comparison of diabatic friction factors as a function of Reynolds number of the multi-tube test section with a protrusion inlet and the single tube with a square-edged inlet at a heat flux of $3 \mathrm{~kW} / \mathrm{m}^{2}$.

To compare the effect of the protrusion inlet to the effect of different pitch ratios, on the diabatic friction factors in the transitional flow regime, the diabatic friction factors at a heat flux of $3 \mathrm{~kW} / \mathrm{m}^{2}$ in the single tube, multi-tube set-ups with a square-edged inlet and pitch ratios of 1.25 and 1.5, and multi-tube set-up with a protrusion inlet and pitch ratio of 1.4, are compared in Fig. 20. Similar to Fig. 18, transition occurred first in the centre tube with the protrusion inlet, and as this inlet caused the greatest inlet disturbance and flow asymmetry, the difference in the critical Reynolds numbers of the three tubes was a maximum. Although free convection effects were able to dampen the inlet effects of the different pitch ratios when a square-edged inlet was used, it was not able to dampen the inlet disturbance of the protrusion inlet, and the results of the multi-tube set-up remained differed significantly from the single tube. Care should therefore be taken during manufacturing to ensure that all the tubes are being installed flush into the header, since a small protrusion significantly affects both the heat transfer and pressure drop results in the transitional flow regime in the tube itself, as well as in the adjacent tubes. 


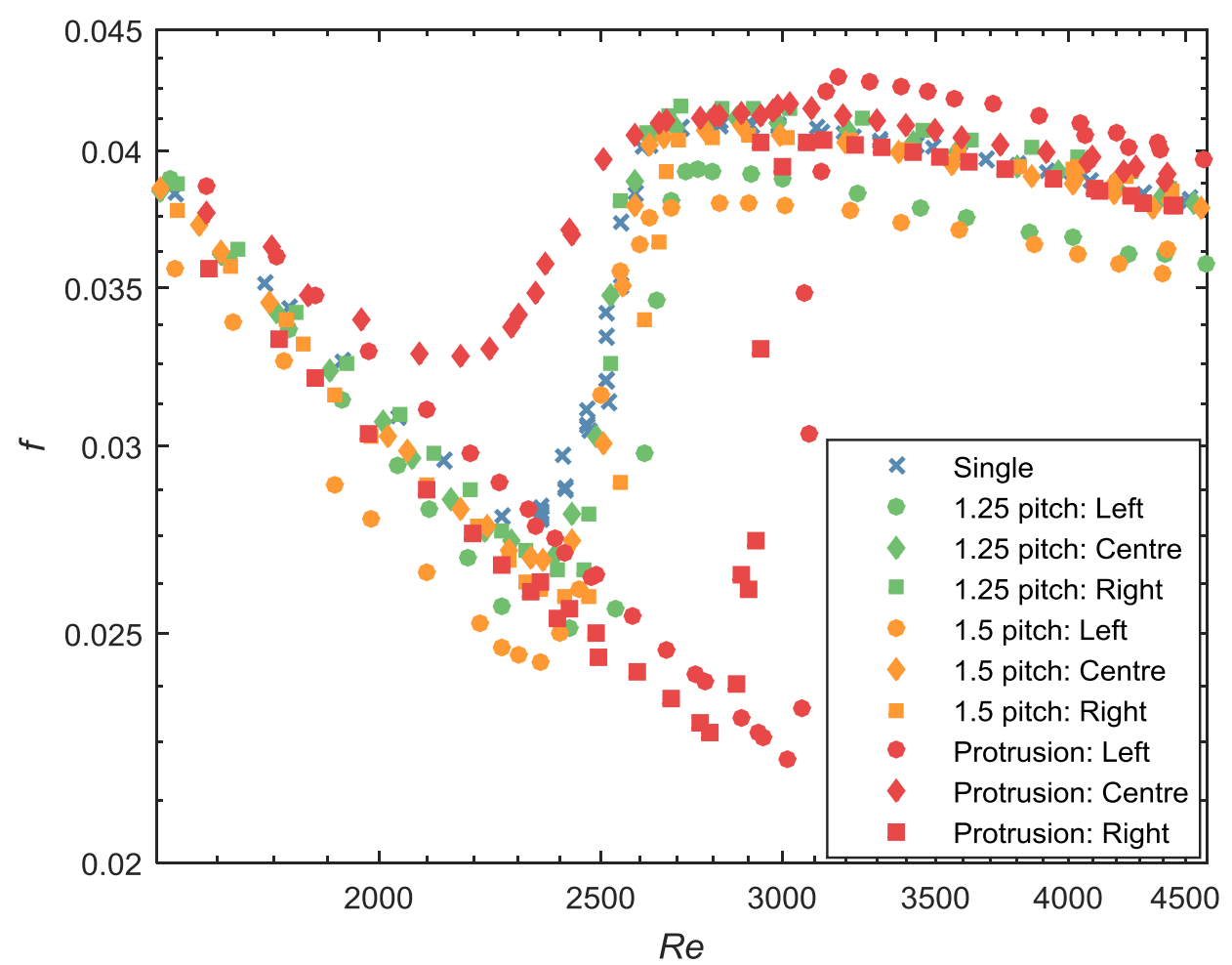

Fig. 20: Comparison of the effect of protrusion on the diabatic friction factors in the transitional flow regime to the effect of different pitch ratios.

\section{Summary}

To summarise the effect of inlet tube spacing and protrusion on flow through multiple circular tubes, Fig. 21 gives a schematic representation of the isothermal and diabatic friction factors as a function of Reynolds number, for multiple tubes with different inlet conditions. For both isothermal (Fig. 21(a)) and diabatic conditions (Fig. 21(b)), maldistribution effects have a negligible effect on the friction factors in the laminar, quasi-turbulent and turbulent flow regimes, while the transitional flow regime is significantly affected.

The effect of the two adjacent tubes on the centre tube, is to dampen the inlet disturbances caused by the square-edged inlet, therefore transition is slightly delayed compared to a single tube (black line 1 and blue line 2 in Fig. 21(a)). As the pitch ratio is increased, the recirculation areas between the tubes increase, which lead to an additional dampening effect of the inlet disturbances in the centre tube, thus transition is further delayed (pink line 4 in Fig. 21(a)). For the two side tubes, the asymmetric velocity profile dominates the inlet disturbances caused by the square-edged inlet. Therefore, transition is significantly delayed and transition gradient increases due to the increased velocity of the fluid (orange line 3 in Fig. 21(a)). As the pitch ratio is increased, the asymmetry in the side tubes 
decreases, and the difference in the critical Reynolds numbers and transition gradients of the multi-tube set-up decrease (pink line 4 and green line 2 in Fig. 21(a)).

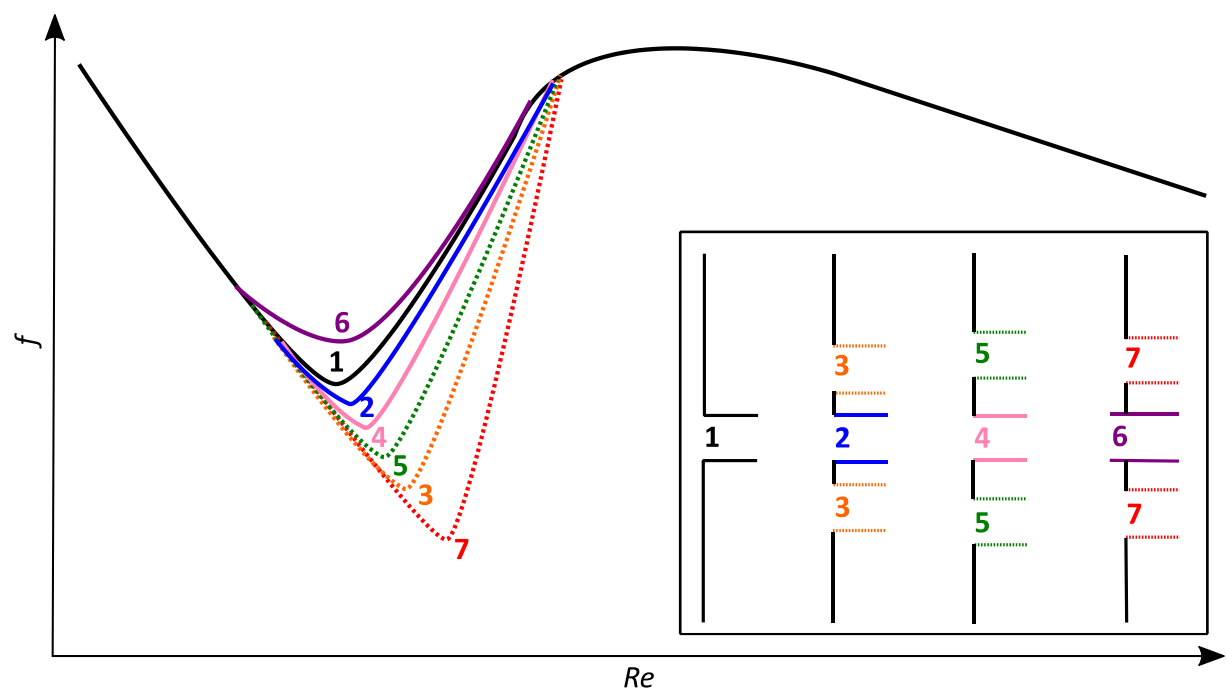

(a)

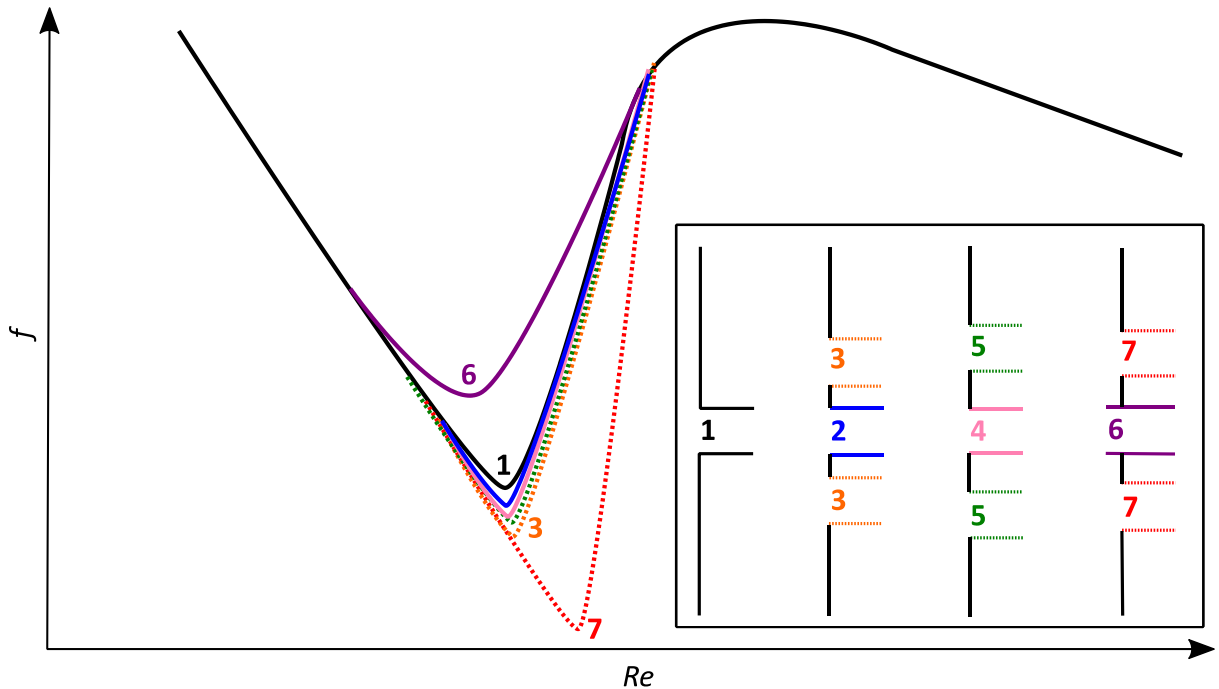

(b)

Fig. 21: Schematic representation of (a) isothermal and (b) diabatic friction factors as a function of Reynolds number for multiple tubes with different inlet conditions. The friction factors in a single tube with a square-edged inlet are represented by the solid black line (1). Solid lines are used for the friction factors in the centre tubes $(2,4$ and 6$)$ of the multi-tube set-up, while dotted lines are used for the side tubes $(3,5$ and 7$)$.

As the re-entrant distance of the protrusion inlet is very small, and the adjacent tubes dampen the inlet disturbance, causing transition in the centre tube to be slightly delayed compared to a single tube with a square-edged inlet (black line 1 and purple line 6 in Fig. 21(a)). However, the protrusion inlet significantly increases recirculation areas between the tubes, which increase the asymmetry of the velocity profile of the two side tubes. The asymmetric velocity profile dominates the inlet disturbances caused by the square-edged 
inlet, thus transition is significantly delayed in the two side tubes (red line 7 in Fig. 21(a)). Furthermore, the increased velocity of the fluid, due to the increased critical Reynolds numbers, led to increased transition gradients in the side tubes.

When heat is applied to the tubes and free convection effects become significant (Fig. 21(b)), the critical Reynolds numbers and transition gradients increase. Furthermore, the inlet disturbances due to the multiple tubes are dampened and the friction factors of the multitube set-up (lines 2-5 in Fig. 21(b)) are similar to that of a single tube (black line 1 in Fig. 21(b)). However, free convection effects are not necessarily able to dampen the effects caused by a protrusion inlet in the centre tube (purple line 6 and red line 7 in Fig. 21(b)). In the centre tube (purple line 6 in Fig. 21(b)), free convection effects cause transition to occur at significantly lower mass flow rates, however, the critical Reynolds number increase due to the decreasing viscosity with increasing temperature. For the two side tubes (red line 7 in Fig. 21(b)), the severe asymmetric velocity profile dominates free convection effects and transition does not occur at significantly lower mass flow rates. However, the critical Reynolds numbers still increase due to the decreasing viscosity with increasing temperature. Although free convection effects cause the transition gradients to increase, the increase was less in the centre tube than in the other tubes, due to the greater inlet disturbance caused by the protrusion inlet.

\section{Conclusions}

Up to now, no work has been done in which maldistribution effects were investigated by considering the effect of adjacent tubes and/or a protrusion at the inlet of a tube. The purpose of this study was therefore to experimentally investigate the maldistribution effects of two adjacent tubes on a centre tube and the effect of the flow asymmetry in the adjacent tubes, as well as the presence of a protrusion inlet effect on two adjacent tubes. Heat transfer and pressure drop measurements were taken between Reynolds numbers of 1000 and 7000 , to ensure that the transitional flow regime, as well as sufficient parts of the laminar and turbulent flow regimes, were covered. Water was used as the test fluid, therefore the Prandtl number ranged between 3 and 7. The tubes were spaced apart at pitches of 1.25, 1.4 and 1.5, and the protrusion distance of the centre tube was $0.1 D$. An isothermal investigation was conducted, as well as diabatic investigations at heat fluxes of $2 \mathrm{~kW} / \mathrm{m}^{2}, 3 \mathrm{~kW} / \mathrm{m}^{2}$ and $4 \mathrm{~kW} / \mathrm{m}^{2}$. 
In both pressure drop and heat transfer results, it was found that neither the different pitch ratios, nor the protrusion inlet, affected the heat transfer and pressure drop characteristics in the laminar and turbulent flow regimes, however, the transitional flow regime was significantly affected. Transition was delayed in the multi-tube set-up, compared to the single tube, however, the delay in transition was more for the left and right tubes than for the centre tube.

From the isothermal friction factors, it was concluded that an increased pitch ratio dampened the inlet disturbances in the centre tube and reduced the flow asymmetry in the side tubes, therefore the differences in the critical Reynolds numbers and transition gradients of the three tubes decreased. As the inlet disturbances were damped in the centre tube, transitional was delayed compared to a single tube with a square-edged inlet. For the side tubes, the increased flow asymmetry led to increased Reynolds numbers, as well as increased transition gradients. As the presence of a protrusion inlet in the centre tube significantly increased the recirculation areas between the tube inlets, the asymmetry of the flow in the side tubes increased, therefore the critical Reynolds number and transition gradient increased significantly compared to the multi-tube set-up with a square-edged inlet.

From the diabatic friction factors and Colburn $j$-factors it was concluded that free convection effects not only led to increased critical Reynolds number and transition gradients, but also decreased the differences between the results of the tubes in the multi-tube set-up when a square-edged inlet was used. However, free convection effects were not able to dampen the inlet disturbances caused by a protrusion inlet. In the centre tube with the protrusion inlet, free convection effects caused transition to occur at significantly lower mass flow rates, while the severe asymmetric velocity profile in the two side tubes dampened free convection effects and transition did not occur significantly earlier. Although transition occurred earlier in the centre tube, the critical Reynolds numbers in all three tubes increased compared to the isothermal results, due to the decreasing viscosity with increasing temperature.

Overall it can therefore be concluded that maldistribution effects caused by adjacent tubes and/or a protrusion at the inlet of a tube significantly affected both the heat transfer and pressure drop characteristics in the transitional flow regime and care should therefore be taken during manufacturing to ensure that all the tubes are being installed flush into the header and the tubes are not spaced too close to each other. 


\section{Acknowledgements}

The funding obtained in South Africa from the NRF, Stellenbosch University/ University of Pretoria Solar Hub, CSIR, EEDSM Hub, RDP and NAC is acknowledged and duly appreciated. This study is a completion of the Masters degree works [52-56] at the university of Pretoria of five students during 2015-2017 under the supervision of the first author, as well as the assistance of the second author while conducting her $\mathrm{PhD}$ on a complimentary project [57].

\section{References}

[1] K.X. Cheng, K.T. Ooi, Investigation of effect of protrusion height on microscale heat transfer and fluid flow in macro geometries, Applied Thermal Engineering, 118 (2017) 244255.

[2] A. Ebrahimi, B. Naranji, An investigation on thermo-hydraulic performance of a flat-plate channel with pyramidal protrusions, Applied Thermal Engineering, 106 (2016) 316-324.

[3] K. Matsubara, T. Miura, H. Ohta, Transport dissimilarity in turbulent channel flow disturbed by rib protrusion with aspect ratio up to 64, Int. J. Heat Mass Transf., 86 (2015) 113-123.

[4] Y. Xie, D. Shi, Z. Shen, Experimental and numerical investigation of heat transfer and friction performance for turbine blade tip cap with combined pin-fin-dimple/protrusion structure, Int. J. Heat Mass Transf., 104 (2017) 1120-1134.

[5] Y. Xie, Z. Shen, D. Zhang, P. Ligrani, Numerical analysis of flow structure and heat transfer characteristics in dimpled channels with secondary protrusions, Journal of Heat Transfer, 138(3) (2016).

[6] L. Zheng, Y. Xie, D. Zhang, Flow and heat transfer characteristics in channels with groove-protrusions and combination effect with ribs, Journal of Heat Transfer, 138(1) (2016).

[7] J. Lee, K.S. Lee, Correlations and shape optimization in a channel with aligned dimples and protrusions, Int. J. Heat Mass Transf., 64 (2013) 444-451.

[8] A.C. Mueller, J.P. Chiou, Review of various types of flow maldistribution in heat exchangers, Heat Transfer Eng, 9(2) (1988) 36-50.

[9] S.H. Tang, M.H. Chng, W.M. Chin, A review of refrigerant maldistribution, Int. J. Automot. Mech. Eng., 10(1) (2014) 1935-1944.

[10] A. Jiao, R. Zhang, S. Jeong, Experimental investigation of header configuration on flow maldistribution in plate-fin heat exchanger, Applied Thermal Engineering, 23(10) (2003) 1235-1246.

[11] S. Lalot, P. Florent, S.K. Lang, A.E. Bergles, Flow maldistribution in heat exchangers, Applied Thermal Engineering, 19(8) (1999) 847-863.

[12] C.C. Wang, K.S. Yang, J.S. Tsai, I.Y. Chen, Characteristics of flow distribution in compact parallel flow heat exchangers, part I: Typical inlet header, Applied Thermal Engineering, 31(16) (2011) 3226-3234.

[13] C.C. Wang, K.S. Yang, J.S. Tsai, I.Y. Chen, Characteristics of flow distribution in compact parallel flow heat exchangers, part II: Modified inlet header, Applied Thermal Engineering, 31(16) (2011) 3235-3242.

[14] S. Salehi, H. Afshin, B. Farhanieh, Numerical investigation of the inlet baffle, header geometry, and triangular fins effects on plate-fin heat exchangers performance, Heat Transfer Eng, 36(16) (2015) 1397-1408.

[15] M. Al-Arabi, Turbulent heat transfer in the entrance region of a tube, Heat Transfer Eng, 3(3-4) (2007) 76-83. 
[16] Y.A. Cengel, A.J. Ghajar, Heat and Mass Transfer: Fundamentals and Applications, 5th ed., McGraw-Hill, 2015.

[17] J.P. Meyer, Heat transfer in tubes in the transitional flow regime, in: 15th International Heat Transfer Conference (IHTC15), Kyoto, Japan, 2014.

[18] H.A. Mohammed, The effect of different inlet geometries on laminar flow combined convection heat transfer inside a horizontal circular pipe, Applied Thermal Engineering, 29(2-3) (2009) 581-590.

[19] J.A. Olivier, J.P. Meyer, Single-phase heat transfer and pressure drop of the cooling of water inside smooth tubes for transitional flow with different inlet geometries (RP-1280), HVAC R Res, 16(4) (2010) 471-496.

[20] J.P. Meyer, J.A. Olivier, Transitional flow inside enhanced tubes for fully developed and developing flow with different types of inlet disturbances: Part I - Adiabatic pressure drops, Int. J. Heat Mass Transf., 54(7-8) (2011) 1587-1597.

[21] J.P. Meyer, J.A. Olivier, Transitional flow inside enhanced tubes for fully developed and developing flow with different types of inlet disturbances: Part II-heat transfer, Int. J. Heat Mass Transf., 54(7-8) (2011) 1598-1607.

[22] J.P. Meyer, J.A. Olivier, Heat transfer and pressure drop characteristics of smooth horizontal tubes in the transitional flow regime, Heat Transfer Eng, 35(14-15) (2014) 12461253.

[23] J.P. Meyer, M. Everts, Single-phase mixed convection of developing and fully developed flow in smooth horizontal circular tubes in the laminar and transitional flow regimes, Int. J. Heat Mass Transf., (2017), Manuscript nr: HMT15378, accepted on 17 October 2017.

[24] M. Everts, J.P. Meyer, Heat transfer of developing and fully developed flow in smooth horizontal tubes in the transitional flow regime, Int. J. Heat Mass Transf., (2017), Manuscript nr: HMT15379, accepted on 17 October 2017.

[25] M. Everts, J.P. Meyer, Relationship between pressure drop and heat transfer of developing and fully developed flow in smooth horizontal circular tubes in the laminar, transitional, quasi-turbulent and turbulent flow regimes, Int. J. Heat Mass Transf., (2017), Manuscript nr: HMT15380, accepted on 17 October 2017.

[26] M. Everts, J.P. Meyer, Flow regime maps for smooth horizontal tubes at a constant heat flux, Int. J. Heat Mass Transf., (2017), Manuscript nr: HMT15381, accepted on 17 October 2017.

[27] J.P. Meyer, S.M. Abolarin, Heat transfer and pressure drop in the transitional flow regime for a smooth circular tube with twisted tape inserts and a square-edge inlet, Int. J. Heat Mass Transf., 117 (2018) 11-29.

[28] J.P. Meyer, T.J. McKrell, K. Grote, The influence of multi-walled carbon nanotubes on single-phase heat transfer and pressure drop characteristics in the transitional flow regime of smooth tubes, Int. J. Heat Mass Transf., 58(1-2) (2013) 597-609.

[29] J. Dirker, J.P. Meyer, D.V. Garach, Inlet flow effects in micro-channels in the laminar and transitional regimes on single-phase heat transfer coefficients and friction factors, Int. J. Heat Mass Transf., 77 (2014) 612-626.

[30] D.D. Ndenguma, J. Dirker, J.P. Meyer, Transitional flow regime heat transfer and pressure drop in an annulus with non-uniform wall temperatures, Int. J. Heat Mass Transf., 108 (2017) 2239-2252.

[31] D.D. Ndenguma, J. Dirker, J.P. Meyer, Heat transfer and pressure drop in annuli with approximately uniform internal wall temperatures in the transitional flow regime, Int. J. Heat Mass Transf., 111 (2017) 429-441.

[32] A. Tubular Exchanger Manufacturers, Standards of Tubular Exchanger Manufacturers Association, New York, 1968. 
[33] M. Everts, Heat transfer and pressure drop of developing flow in smooth tubes in the transitional flow regime, Masters dissertation, University of Pretoria, Pretoria, 2014.

[34] A.J. Ghajar, K.F. Madon, Pressure drop measurements in the transition region for a circular tube with three different inlet configurations, Exp. Therm. Fluid Sci., 5(1) (1992) 129-135.

[35] R. Rayle, Influence of orifice geometry on static pressure measurements, American Society of Mechanical Engineers, 1959.

[36] A. Bakker, R.D. LaRoche, E.M. Marshall, Laminar flow in static mixers with helical elements, in: The Online CFM Book, 2000.

[37] C.O. Popiel, J. Wojtkowiak, Simple formulas for thermophysical properties of liquid water for heat transfer calculations [from $\mathrm{O}^{\circ} \mathrm{C}$ to $150^{\circ} \mathrm{C}$ ], Heat Transfer Eng, 19(3) (1998) 87-101.

[38] A. Steels, Atlas Grade Data Sheet 316 316L 316H, in, 2011.

[39] A.J. Ghajar, J. Kim, Calculation of local inside-wall convective heat-transfer parameters from measurements of local outside-wall temperatures along an electrically heated circular tube, in: M. Kutz (Ed.) Heat-Transfer Calculations, McGraw-Hill, New York, 2006, pp. 23.23-23.27.

[40] S.M. Morcos, A.E. Bergles, Experimental investigation of combined forced and free laminar convection in horizontal tubes, Journal of Heat Transfer, 97(2) (1975) 212-219.

[41] F. Bozzoli, L. Cattani, S. Rainieri, Effect of wall corrugation on local convective heat transfer in coiled tubes, Int. J. Heat Mass Transf., 101 (2016) 76-90.

[42] F. Bozzoli, L. Cattani, S. Rainieri, F.S. Viloche Bazán, L.S. Borges, Estimation of the local heat-transfer coefficient in the laminar flow regime in coiled tubes by the Tikhonov regularisation method, Int. J. Heat Mass Transf., 72 (2014) 352-361.

[43] G. Maranzana, I. Perry, D. Maillet, Mini- and micro-channels: influence of axial conduction in the walls, Int. J. Heat Mass Transf., 47(17) (2004) 3993-4004.

[44] L.M. Tam, Transitional heat transfer in plain horizontal tubes, Heat Transfer Eng, 27(5) (2006) 23-38.

[45] B. Metais, E. Eckert, Forced, mixed, and free convection regimes, Journal of Heat Transfer, 86(2) (1964) 295-296.

[46] F.M. White, Fluid Mechanics, 6th ed., McGraw-Hill, Singapore, 2009.

[47] R.G. Deissler, Analytical investigation of fully developed laminar flow in tubes with heat transfer with fluid proprties variable along the radius, NACA TN2410, National Aeronautics and Space Administration, Washington, 1951.

[48] R. Allen, E. Eckert, Friction and heat-transfer measurements to turbulent pipe flow of water ( $\operatorname{Pr}=7$ and 8) at uniform wall heat flux, Journal of Heat Transfer, 86(3) (1964) 301310.

[49] L.M. Tam, A.J. Ghajar, Effect of Inlet Geometry and Heating on the Fully Developed Friction Factor in the Transition Region of a Horizontal Tube, Exp. Therm. Fluid Sci., 15(1) (1997) 52-64.

[50] H.K. Tam, L.M. Tam, A.J. Ghajar, Effect of inlet geometries and heating on the entrance and fully-developed friction factors in the laminar and transition regions of a horizontal tube, Exp. Therm. Fluid Sci., 44 (2013) 680-696.

[51] A.J. Ghajar, L.M. Tam, Heat transfer measurements and correlations in the transition region for a circular tube with three different inlet configurations, Exp. Therm. Fluid Sci., 8(1) (1994) 79-90.

[52] F.A. Mulock-Houwer, The effect of adjacent tubes on the diabatic friction factors in the transitional flow regime, Masters dissertation, University of Pretoria, Pretoria, 2016. 
[53] E.S. Vause, The inlet effects of multiple tubes on the adiabatic pressure drop of smooth horizontal tubes in the transitional flow regime, Masters dissertation, University of Pretoria, Pretoria, 2016.

[54] A.T.C. Hall, The Effect of Inlet Header Geometry on the Heat Transfer Performance of Smooth Horizontal Tubes in the Transitional Regime, Masters dissertation, University of Pretoria, Pretoria, 2017.

[55] M. Joubert, The influence of a multiple tube inlet condition on fully-developed friction factors in the transitional flow regime, Masters dissertation, University of Pretoria, Pretoria, 2017.

[56] L.M.J. Pallent, The influence of a multiple tube inlet condition on heat transfer in the transitional flow regime, Masters dissertation, University of Pretoria, Pretoria, 2017.

[57] M. Everts, Single-phase mixed convection of developing and fully developed flow in smooth horizontal circular tubes in the laminar, transitional, quasi-turbulent and turbulent flow regimes, $\mathrm{PhD}$ thesis, University of Pretoria, Pretoria, 2017. 